\title{
Review of Literature on Terminal Box Control, Occupancy Sensing Technology and Multi-zone Demand Control Ventilation (DCV)
}
G Liu
J Zhang
A Dasu

March 2012

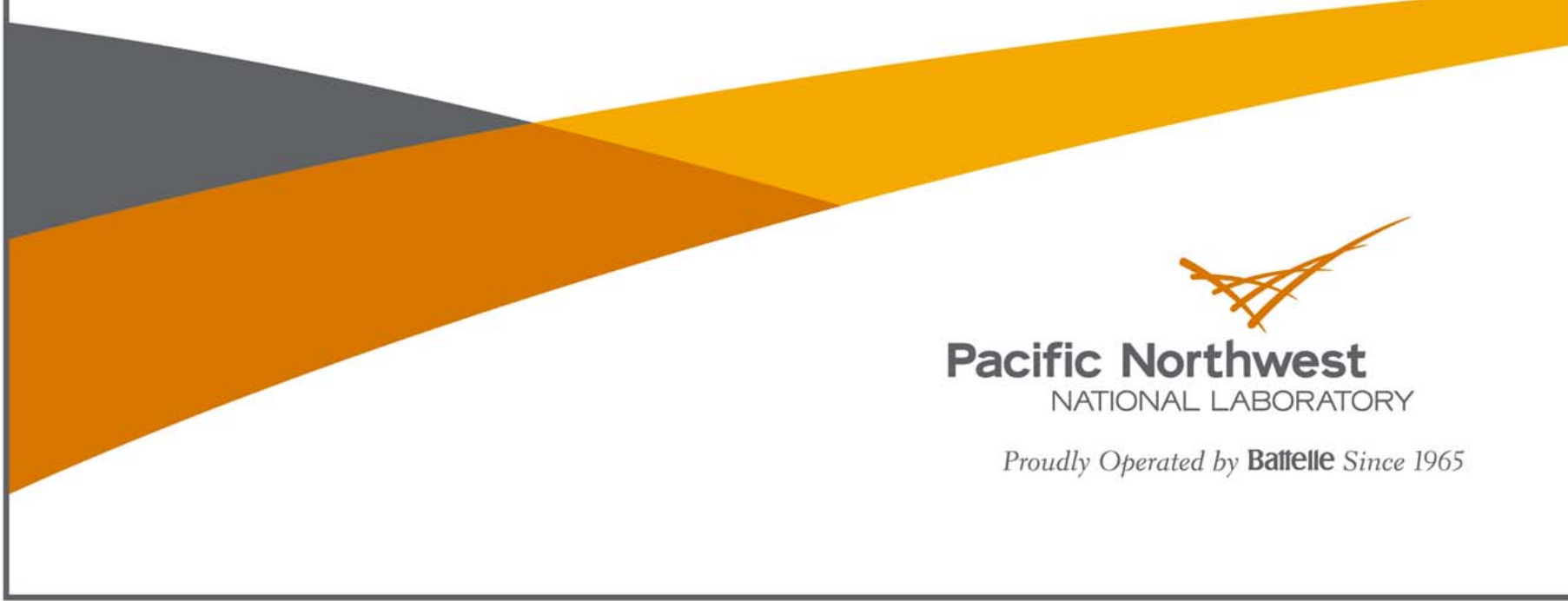




\section{DISCLAIMER}

This report was prepared as an account of work sponsored by an agency of the United States Government. Neither the United States Government nor any agency thereof, nor Battelle Memorial Institute, nor any of their employees, makes any warranty, express or implied, or assumes any legal liability or responsibility for the accuracy, completeness, or usefulness of any information, apparatus, product, or process disclosed, or represents that its use would not infringe privately owned rights. Reference herein to any specific commercial product, process, or service by trade name, trademark, manufacturer, or otherwise does not necessarily constitute or imply its endorsement, recommendation, or favoring by the United States Government or any agency thereof, or Battelle Memorial Institute. The views and opinions of authors expressed herein do not necessarily state or reflect those of the United States Government or any agency thereof.

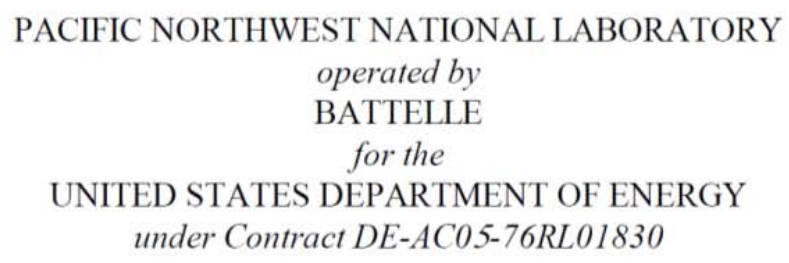

Printed in the United States of America

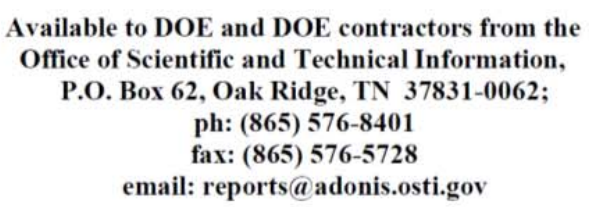

Available to the public from the National Technical Information Service, U.S. Department of Commerce, 5285 Port Royal Rd., Springfield, VA 22161 ph: (800) 553-6847 fax: (703) 605-6900 email: orders@ntis.fedworld.gov online ordering: http://www.ntis.gov/ordering.htm 
PNNL- 21281

\section{Review of Literature on Terminal Box Control, Occupancy Sensing Technology and Multi-zone Demand Control Ventilation (DCV)}

G Liu

J Zhang

A Dasu $^{1}$

March 2012

Prepared for

U.S. Department of Energy

under Contract DE-AC05-76RL01830

Pacific Northwest National Laboratory

Richland, Washington 99352

${ }^{1}$ Energy Dynamics Laboratory (EDL), Logan, Utah. 



\section{Executive summary}

This report presents the results of an analysis of published studies and other literature concerned with terminal box control, occupancy sensing technology, and multi-zone demand control ventilation (DCV) in commercial buildings. To meet the ventilation needs of building occupants, heating, ventilating and airconditioning systems provide outdoor air. For many systems, air is brought into a commercial building through air-handling units, which supply conditioned air to many thermal zones in the building. The airhandling units mix outdoor air in a controlled proportion with recirculated air and then cool the mixture before distribution to the terminal boxes. Terminal boxes usually serve a single building zone, controlling the air flow rate to the zone and reheating the air, if it is too cool for the zone served. Each terminal box has a minimum air flow rate set so that it meets the ventilation requirements of the occupants of the zone the box serves. This minimum air flow rate is commonly designed as a constant value based on the design occupancy of the zone served, which usually corresponds to the maximum occupancy.

In practice, control system integrators and installers often set the minimum air flow rate for ventilation to between $30 \%$ and $50 \%$ of the terminal box maximum air flow rate. Building occupancy, however, varies dynamically. Conference rooms, cafeterias, break rooms, auditoriums, and other assembly spaces are often unoccupied for significant periods of time. Office occupancy varies during the course of a work day, from day to day, and over the longer term because of meetings in the office, attendance of meetings elsewhere, business travel, changing room functions during remodeling, and variations in staffing. The resulting over-ventilation, during times when the space has less than maximum occupancy or is unoccupied, wastes significant fan power, resulting in energy waste, and even causing discomfort for occupants in some spaces (e.g., conference rooms) from overcooling.

Carbon-dioxide-based demand control ventilation has existed for a number of years; however, as currently used, it controls outdoor-air intake by the air handler only, not ventilation of individual zones or rooms. The need for frequent recalibration (e.g., annually) and the high cost of installation for each zone (or room) makes $\mathrm{CO}_{2}$-based control of ventilation at terminal boxes impractical. A multi-lab report (Brambley et al. 2005) for the U.S. Department of Energy (DOE) on advanced sensors and controls identifies a need for "development of sensors to determine occupancy number and population distribution within buildings." There are no such terminal unit controllers on the market today to modulate air flow to zones based on actual occupancy.

The Advanced Energy Retrofit Guide (AERG) for Office Buildings, sponsored by DOE's Building Technology Program (BTP), reveals that a $4 \%$ reduction in whole-building energy consumption can be achieved by implementing occupancy-based control (OBC) in conference rooms alone (Liu et al. 2011).

This report presents an overview of the relevant requirements of standards and the status of terminal box control, occupancy sensing technology, and demand controlled ventilation. Key conclusions are:

\section{- Although DCV for single-zone systems is relatively mature, little design guidance or definitive information on DCV performance for multi-zone systems is available.}


System-specific guidance for use of DCV is available for single-zone systems, but application guidance for multi-zone variable air volume (VAV) systems is not. No case studies of actual multi-zone implementations using $\mathrm{CO}_{2}$-based DCV were found.

- Constant minimum air flow set points determined using rules of thumb are still common in the field, leading to excessive energy consumption and occupant discomfort.

Published research and field experience show that constant minimum air flow set points cause excessive fan power consumption and energy use for reheating.

- Occupancy-based control for terminal boxes could mitigate energy waste and discomfort from overventilation but will require further development before becoming compatible with the market.

Occupancy-based control for terminal boxes could mitigate these sources of wasted energy. Key to accomplishing this is a low-cost technology for sensing the actual occupancy number for building zones in real time. Several technologies show promise, but none currently fully meet the need with adequate accuracy and sufficiently low cost. Further developments are needed to enhance capabilities and reduce the cost of both the hardware and the installation/commissioning of occupancy number sensing systems. This will require developing efficient sensing algorithms that can be ported to the lowest-cost microprocessors. Moreover, the sensing devices will likely need capabilities for self-commissioning to minimize the time requirements and costs for installation and commissioning. Only with such advancements will occupancy sensing become practical and appealing to the market.

- Algorithms for terminal box control using occupancy sensing need to be developed in parallel with development of practical, market compatible occupancy number sensing technology.

In addition to occupancy sensing technology, application to terminal box control will require the development of algorithms that control flow rates based on the actual real-time data from occupancy sensors. Application of the resulting technology will increase the efficiency of HVAC systems and save significant energy and expense. ${ }^{2}$

- Development of new occupancy sensing based control must ensure compatibility with constantly evolving standards for ventilation and building energy efficiency.

The development of new control strategies for terminal boxes must consider their relationships to ventilation standards, which set minimum values for outdoor-air ventilation rates, and building energy standards, which establish maximum values for ventilation to control energy consumption. These standards are continuously evolving, so new control technology must maintain compatibility with their evolving requirements.

\footnotetext{
${ }^{2}$ The statement of work for the project under which the work documented in this report was performed calls for a detailed assessment of potential impacts of occupancy-based terminal box control on energy use and its associated cost by the end of fiscal year 2012.
} 


\section{Acknowledgements}

The authors wish to acknowledge the contributions and valuable assistance provided by the staff of the U.S. Department of Energy (DOE), Office of Energy Efficiency and Renewable Energy (EERE), through the Building Technologies Program. Specifically, we would like to thank Alan Schroeder, for providing the resources and support. We'd like to thank our internal review team, Dr. Michael Brambley and Linda Sandahl, for their leadership and help. We would also like to thank Dr. Young-hum Cho of the Kumoh National Institute of Technology, South Korea, for his close collaboration on terminal box control review and support on developing the schematic diagrams. Finally, the authors would like to extend their appreciation to Sue Arey and Lorena Ruiz for their conscientious, team-oriented, and high quality assistance they brought to this document. 


\section{Contents}

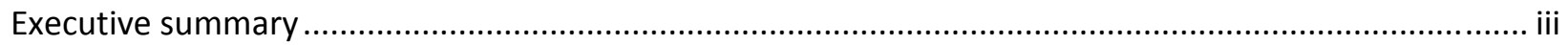

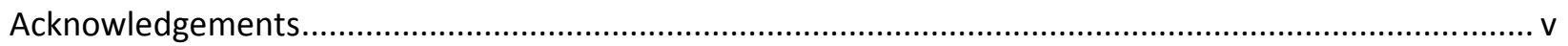

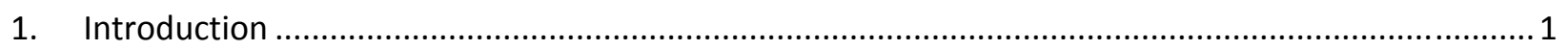

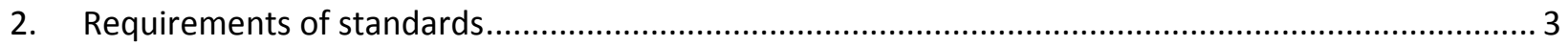

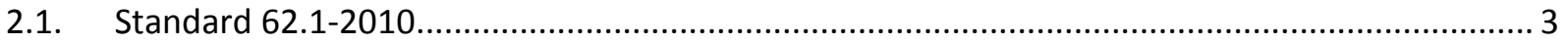

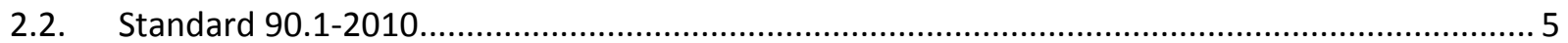

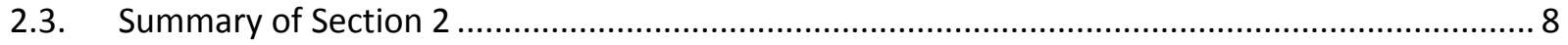

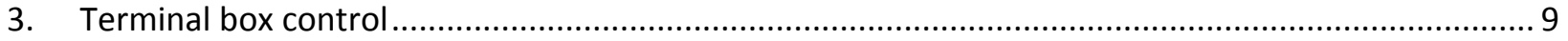

3.1 Introduction of terminal box types and control .................................................................. 9

3.2 Minimum air flow rate settings for terminal boxes ................................................................ 13

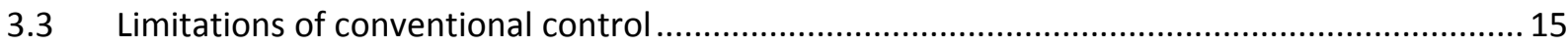

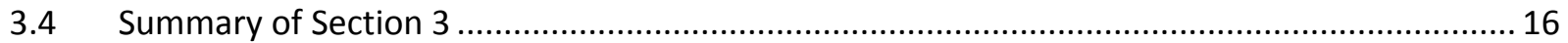

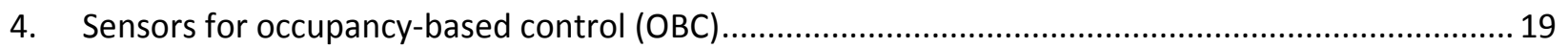

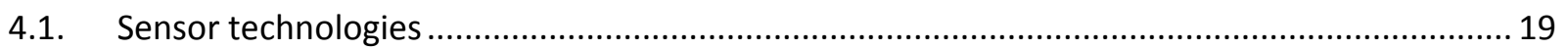

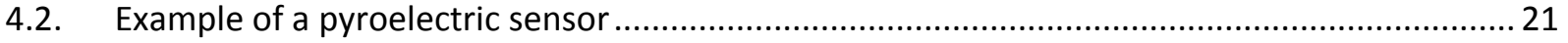

4.3. Other occupancy sensor technology under development ................................................... 24

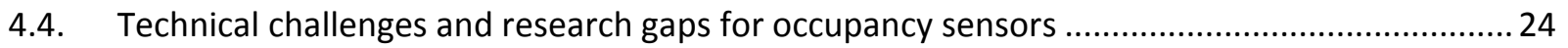

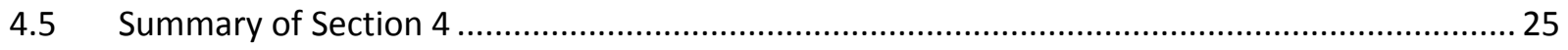

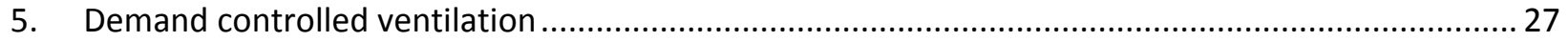

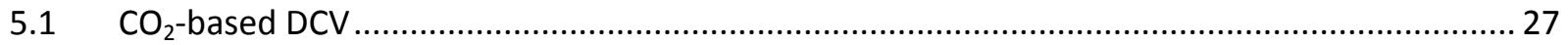

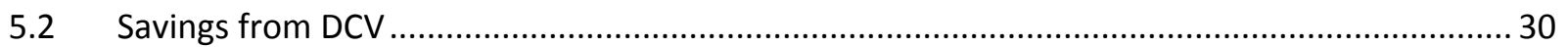

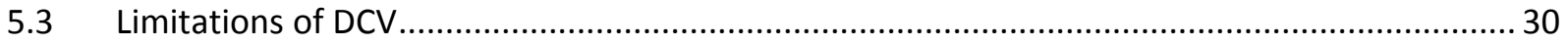

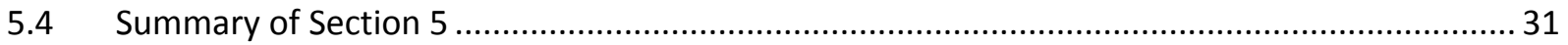

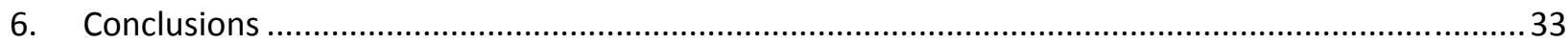

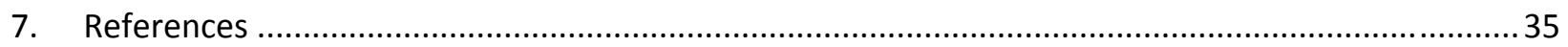




\section{Figures}

Figure 1 Single-maximum Terminal Box Control Sequence (Thornton et al. 2011) ................................. 7

Figure 2 Dual-maximum Terminal Box Control Sequence (Thornton et al. 2011)................................... 7

Figure 3 Schematic diagram of single-duct constant volume terminal box ............................................ 9

Figure 4 Schematic diagram of single-duct variable-volume pressure-dependent terminal box without

reheat

Figure 5 Schematic diagram of a single-duct variable-volume pressure-dependent terminal box with reheat

Figure 6 Schematic diagram of single-duct variable-volume pressure-independent terminal box with reheat. 13

Figure 7 Theory of passive infrared sensors . 22

Figure 8 Example of detecting direction of occupant motion ...... .23

Figure $9 \mathrm{CO}_{2}$-based DCV control schematic for single-zone systems

\section{Tables}

Table 1 Summary of DCV energy savings (Brambley et al. 2005). 


\section{Introduction}

The primitive function of buildings was to serve as shelters to protect people from harsh outdoor conditions, such as extreme temperatures. Since mechanical air-conditioning systems were invented, humans have been capable of controlling their indoor environments, including ventilation and temperature. The 1970s energy crises drove designers to create airtight building envelopes and to reduce mechanical ventilation resulting in isolated indoor air quality (IAQ) issues and "sick building syndrome" in some buildings. Experimental studies helped establish the relationship between the ventilation rate per person and perceived indoor air quality, which became the foundation of the current ventilation standards and regulations. For most commercial building spaces (where occupants are the major source of contaminants), current standards prescribe two ventilation rates, one intended to dilute the contaminants generated by occupants and the other for building-related sources of air contaminants.

To maintain adequate ventilation for occupants, the minimum air flow rate for heating, ventilation and air conditioning (HVAC) terminal boxes is commonly designed to a constant value based on the design occupancy of the zone served, which usually corresponds to maximum occupancy. In practice, control system integrators and installers often set the minimum air flow rate for ventilation in the range of $30 \%$ to $50 \%$ of the terminal box maximum airflow rate. The occupancy of building spaces, however, varies dynamically. The resulting over-ventilation during times when a space has less than maximum occupancy or is unoccupied wastes significant fan power and even causes discomfort for occupants in some spaces (e.g., conference rooms) from overcooling. The Advanced Energy Retrofit Guide (AERG) for Office Buildings (Liu et al. 2011) sponsored by the U.S. Department of Energy's Building Technologies Program, reveals that a $4 \%$ reduction in whole-building energy consumption can be achieved by implementing occupancy-based control (OBC) in conference rooms alone. The present report presents an overall review of the relevant requirements of standards and the status of terminal box control, occupancy sensing technology, and demand controlled ventilation (DCV). It also identifies technology and research gaps that would significantly increase the energy efficiency of building space conditioning by using occupancy number sensing and new algorithms for terminal boxes to control ventilation rates of individual building zones, thus eliminating over-ventilation of unoccupied and lightly occupied spaces. 


\section{Requirements of standards}

Conditioning ventilation air can consume significant cooling, heating and fan energy; therefore, most mechanical systems are designed to meet minimum ventilation requirements, which are defined by regulations and standards like ANSI/ASHRAE Standard 62.1 Ventilation for Acceptable Indoor Air Quality (ANSI/ASHRAE 2010). The standard not only prescribes the rate at which outdoor air must be delivered to each thermal zone of a building but also prescribes how to calculate the outdoor-air flow rate needed at the system level, which greatly affects ventilation system designs and controls. Building energy standards like Standard 90.1 Energy Standard for Buildings Except Low-rise Residential Buildings (ANSI/ASHRAE/IESNA 2010) refers to Standard 62.1-2007 (ANSI/ASHRAE 2007) and also has provisions for ventilation system design. This section summarizes the ventilation requirements in the latest versions of these standards and the major changes to the requirements that occurred during updates to previous versions. Although the latest standards have yet to be adopted widely, they likely will be in a few years and their provisions, therefore, portend future design trends.

\subsection{Standard 62.1-2010}

Standard 62.1, Ventilation for Acceptable Indoor Air Quality (ANSI/ASHRAE 2010), requires building ventilation systems to follow one of its three procedures to meet ventilation requirements.

- Ventilation rate procedure (VRP)

- IAQ procedure

- Natural ventilation procedure.

The VRP prescribes the design method by which outdoor air intake rates are determined based on space type, occupancy density, and floor area. The IAQ procedure is a performance-based approach. It requires designers to first identify the source, concentration limit, and the corresponding exposure period for each contaminant or contaminant mixture of concern. A target percentage of occupants to maintain satisfied with the indoor air quality is also established (usually $80 \%$ or greater). A mass balance is then used to determine the minimum outdoor-air flow rate required to maintain the contaminant concentrations below their limits. After installation of the system and occupancy of the building or spaced served by it, the standard requires a subjective evaluation by occupants (e.g., a survey) regarding their satisfaction with the indoor air quality. If the percentage of occupants satisfied is less than the target percentage, the minimum outdoor-air flow rate for ventilation is increased to a point at which the target percentage of occupants satisfied with the air quality is reached or exceeded. The natural ventilation procedure permits outdoor air ventilation to be provided through exterior openings in the building envelop (such as operable windows) to comply with the standard. However, to rely on natural ventilation alone, a building must have openings that are always open during occupied periods, have an engineered natural ventilation system approved by the cognizant local authority, or have no heating and cooling equipment.

Most mechanically ventilated buildings follow the ventilation rate procedure because it is a prescriptive path and, therefore, easy to use. A set of equations in this procedure determines the outdoor-air intake 
flow rate for the system, which is intended to provide breathing zones (a vertical zone located approximately at the height of a seated person), when occupied, with sufficient ventilation air to dilute the contaminants generated by occupants and other sources. Janssen (1999) and Stanke (1999) summarized the history of ventilation practice in the first century of air conditioning. In early versions of Standard 62.1 (ANSI/ASHRAE 1989, 1999, 2001), the zone ventilation requirement is specified based on either the number of occupants in the zone or the floor area of the zone, i.e., either

$$
V_{b z}=R_{p} \cdot P_{z}
$$

or

$$
V_{b z}=R_{a} \cdot A_{z}
$$

More recent versions (ANSI/ASHRAE 2004, 2007, 2010) prescribe the combination of the two ventilation rates. The rate per person is intended to dilute the contaminants generated by occupants and the other, rate per occupied area, is for building-related sources. The breathing zone ventilation requirement is calculated based on.

$$
V_{b z}=R_{p} \cdot P_{z}+R_{a} \cdot A_{z}
$$

where $V_{b z}$ is the required volumetric flow rate for outdoor air into the breathing zone, $\mathrm{ft}^{3} / \mathrm{min}$ (or L/s), $R_{p}$ is the outdoor-air flow rate required per person as determined from Table 6-1 of ASHRAE Standard 62$2010, \mathrm{ft}^{3}$ /min-person (or L/s-person), $\mathrm{P}_{\mathrm{z}}$ is the zone population (i.e., the largest number of persons expected to occupy the zone during typical use), in persons, $R_{a}$ is the outdoor-air flow rate required per unit of floor area as determined from Table 6-1 ASHRAE Standard 62- 2010, $\mathrm{ft}^{3} / \mathrm{min}$ per $\mathrm{ft}^{2}$ of floor area (or $\mathrm{L} / \mathrm{s}-\mathrm{m}^{2}$ ), and $\mathrm{A}_{\mathrm{z}}$ is the zone floor area, $\mathrm{ft}^{2}\left(\mathrm{or}^{2}{ }^{2}\right.$ ).

Another important update from Standard 62.1-2001 (ANSI/ASHRAE 2001) to Standard 62.1-2004 (ANSI/ASHRAE 2004) improved the calculation for multi-zone recirculating systems, especially for multizone variable-air-volume (VAV) systems. Before the update, the system outdoor intake rate was simply the sum of the individual zone ventilation requirements. In the 2004, 2007, and 2010 versions, the calculation procedure can be summarized in seven steps:

Step 1. Calculate breathing-zone outdoor-air flow rate

Step 2. Determine the zone air distribution effectiveness

Step 3. Calculate the zone outdoor-air flow rate

Step 4. Calculate the zone primary outdoor-air fraction (or zone discharge outdoor-air fraction)

Step 5. Determine the uncorrected outdoor-air intake rate

Step 6. Determine the system ventilation efficiency

Step 7. Calculate the system outdoor-air intake rate.

This new procedure accounts for over-ventilation to the noncritical zones of the variable-air-volume (VAV) system and system ventilation effectiveness. However, it often results in a higher design outdoor- 
air intake rate for the system than that calculated using the simple summation method in the older standards. The ventilation system outdoor-air intake flow rate determined using the VRP for multi-zone recirculating systems is a peak rate based on worst-case operating conditions. Although these conditions may take place for only very short times, HVAC equipment must be sized for worst case scenarios. To reduce the energy impact and account for changes in operating conditions, three options of dynamic reset are allowed (but not required) by Standard 62.1-2010:

- Demand-controlled ventilation (DCV)

- Ventilation efficiency

- Outdoor-air fraction.

DCV option: "Any means by which the breathing zone outdoor-air flow can be varied to the occupied space or spaces based on the actual or estimated number of occupants and/or ventilation requirements of the occupied zone." (ANSI/ASHRAE 2010). This is a zone-level control strategy, and it is discussed in Section 5 of this report.

Ventilation efficiency option: In multi-zone systems, as the zone-air distribution efficiency changes from heating to cooling mode, or as the zone air flow rate changes with variations in building load, the system ventilation efficiency changes. This option allows dynamically resetting either or both the zone minimum air flow set points (for VAV systems) and the system outdoor-air intake rate in response to the system ventilation efficiency changes.

Outdoor-air fraction option: In most VAV systems, each terminal unit has a minimum air flow setting. When an outdoor-air economizer is activated, the system uses more outdoor air for free cooling. During economizing, minimum air flow rate set points for VAV boxes can be reset downward because the primary air is richer in outdoor-air content, possibly reducing fan energy use and reheat.

Although all three options may result in the system outdoor-air intake rate differing from its design value, they focus on different system or zone operation situations. The reset for DCV is in response to the zone occupancy changing; the ventilation efficiency option changes in response to the zone air flow rate changing because the load changes. Both of these options are independently written in ASHRAE 90.1-2010 (ANSI/ASHRAE/IESNA 2010). When a particular building design falls into both categories, both reset options may be required to meet the standard. The outdoor-air fraction option is optional and not required. All reset options provide energy saving opportunities, but they also require a building control system and hardware for implementation. This topic is discussed further in Section 5.3.

\subsection{Standard 90.1-2010}

The purpose of Standard 90.1, Energy Standard for Buildings Except Low-Rise Residential Buildings (ANSI/ASHRAE/IESNA 2010), is to provide requirements that ensure that buildings are designed to be 
energy efficient. For minimum ventilation requirements, Standard 90.1 refers to the applicable standard for ventilation, 62.1 .

Section 6.5.2.1 of Standard 90.1, which addresses multi-zone VAV systems with terminal box reheat, requires that the minimum damper positions be the higher of

- $30 \%$ for single-maximum terminal box control (see Figure 1 ) or $20 \%$ for dual-maximum terminal box control (see Figure 2) and

- zone ventilation requirement based on Standard 62.1.

In Section 6.4.3.9 of Standard 90.1-2010, DCV is required for spaces larger than $500 \mathrm{ft}^{2}$ with the design occupancy for ventilation of greater than 40 people per $1000 \mathrm{ft}^{2}$ of floor area and served by systems with one or more of the following:

- an air-side economizer,

- automatic modulating control of the outdoor-air damper, or

- a design outdoor-air flow rate greater than $3000 \mathrm{cfm}$.

Multiple-zone systems without direct digital control (DDC) of individual zones that communicate with a central control panel are exempted from this requirement because without DDC, the time-dependent zone ventilation requirement (based on occupancy) cannot be used to control the outdoor-air intake rate.

To obtain energy savings from another option of dynamic ventilation reset, Section 6.5.3.3 of Standard 90.1-2010 requires that multiple-zone VAV systems with DDC control of terminal units include methods to automatically reduce the outdoor-air intake flow rate below the design rate in response to changes in system ventilation efficiency, as defined by Standard 62.1-2007, Appendix A. Based on the discussion of ventilation efficiency option in Section 2.1, this may include reset of either or both zone minimum air set points (for VAV systems) and outdoor-air flow rates. Stanke (2010) provides an overview of the calculation steps required in Standard 62.1 and a discussion of the benefits of dynamic reset for multizone systems. 


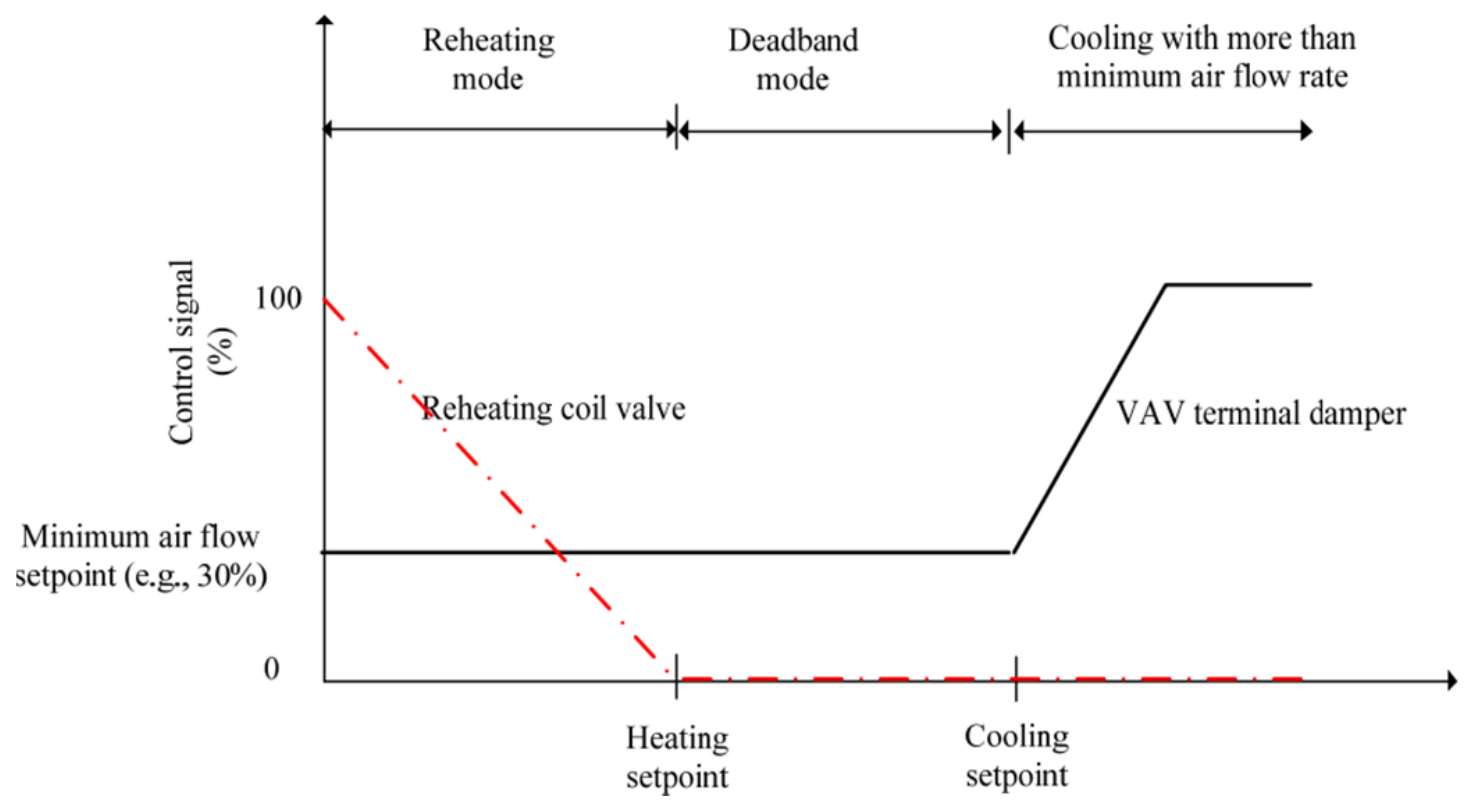

Figure 1 Single-maximum Terminal Box Control Sequence (Thornton et al. 2011)

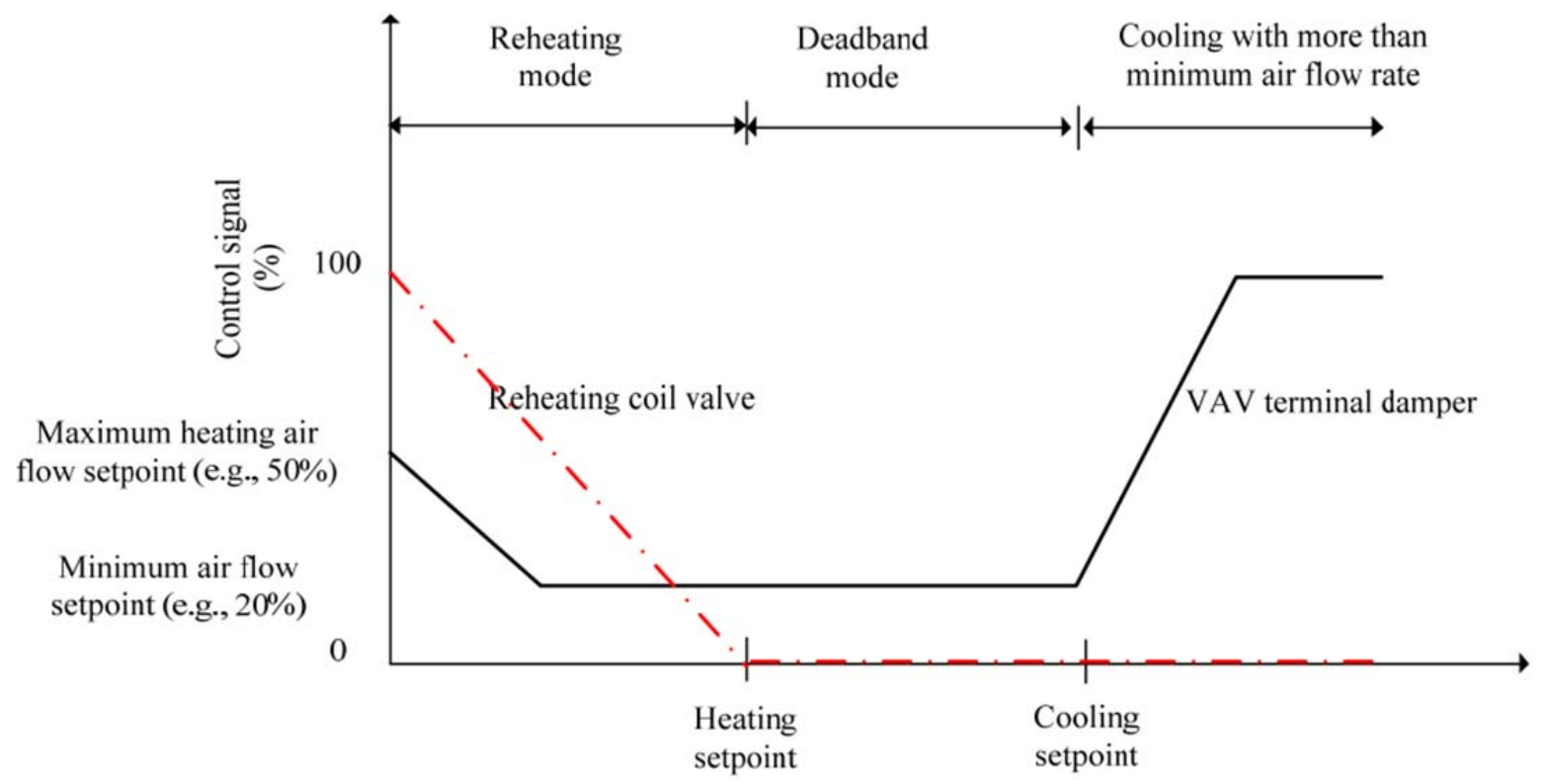

Figure 2 Dual-maximum Terminal Box Control Sequence (Thornton et al. 2011) 


\subsection{Summary of Section 2}

Energy-efficient designs have to meet minimum ventilation requirements such as the VRP in Standard 62.1-2007. Because the system outdoor-air intake rate is determined based on worst-case operating conditions, three options of dynamic reset in response to the changes in operating conditions are allowed. Standard 90.1-2010 requires two of the options (DCV and multiple-zone VAV system ventilation optimization control) for applicable systems and space. If a zone is densely occupied, and it is served by a multi-zone VAV system with DDC central control of the terminal units, this system and space may be required to have both $D C V$ and multiple-zone VAV system ventilation optimization control to comply with the Standard 90.1. An example is a multi-zone VAV system serving a large conference room with one or multiple terminal boxes. 


\section{Terminal box control}

Single-duct VAV air-handling units (AHUs) are one of the most popular systems in the U.S. today. Terminal boxes are critical components of VAV systems. The minimum air flow rate of terminal boxes is a key factor influencing comfort, indoor air quality and energy cost (Cho and Liu 2008, 2009). The terminal box system types, control methods, minimum air flow settings in common practice, and advanced control are discussed in this section.

\subsection{Introduction of terminal box types and control}

The objective of this section is to review the technology and development of VAV terminal boxes. Currently, a constant minimum air flow rate is used in most applications, which results in comfort issues and wasted energy. The terminal box includes all or a subset of the following components: a damper, heating coil, flow measurement station, and controller .

\subsubsection{Single duct constant air volume (CAV) systems}

Constant volume (CV) systems were installed in the 1950s and 1960s. Constant volume systems depend on reheating to control the temperatures of zones whenever zone loads are less than their design values. "Reheat at the $\mathrm{CV}$ terminal box is a true year-round requirement because actual full load design conditions may exist for only a relatively few operating hours" (Chen and Demster, 1995).

A schematic diagram of a single-duct CV terminal box is shown in Figure 3. The terminal box consists of a reheat coil and its associated control valve, a zone temperature sensor, and a controller. The central airhandling unit supplies constant-temperature air , and a manual balancing damper in each zone is set in a fixed position to control the amount of air delivered to the zone served by the terminal box.

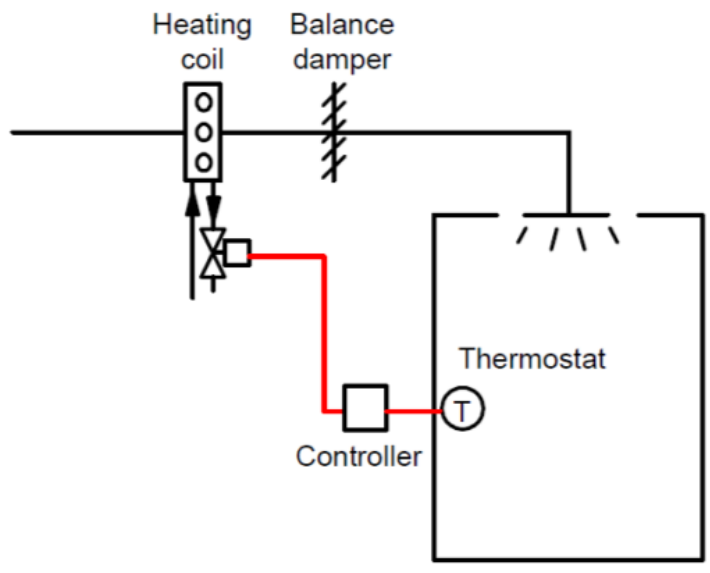

Figure 3 Schematic diagram of single-duct constant volume terminal box

The single-duct constant volume terminal box has a single closed control loop. The controlled variable is the room air temperature, which is sensed by a temperature sensor, which is often part of a thermostat unit. The control device is the terminal box reheat valve. The controller compares the actual room 
temperature from the sensor with the room temperature set point. If the actual sensed room temperature is lower than the set point, the controller increases the control valve open position to increase the heat output of the heating coil. If the sensed room temperature is greater than the set point, the controller decreases the heating valve opening. When the room temperature is within the dead band around the set point, the controller makes no change in the valve position. The single-duct constant volume terminal box has a relatively low initial cost and simple control requirements and can provide high ventilation rates.

All air delivered to terminal boxes is cooled in the air-handling unit sufficiently to satisfy the zone with the largest cooling load, and air delivered to other zones must then be reheated to prevent overcooling. As a result, CAV terminal boxes consume excess reheat energy and waste fan power. They also generate noise because of their high air velocities. CAV units may cause potential humidity issues when the supply-air temperature is increased to save heating and/or cooling energy. The CAV system has a higher energy cost than other types of terminal boxes (descriptions of which are provided in the sections that follow) because they use more reheat.

\subsubsection{Single-duct VAV pressure-dependent terminal boxes without reheat}

"Successful early VAV product research and development in the United States led to the production of energy efficient terminal boxes in the 1960s and the genesis of the system as we know it today" (Smeed, 2007). Development of VAV technology started as early as the 1940 s. Initial efforts used space temperature sensors to provide limited modulation of flow rates. In the 1960s, development of a ceiling diffuser that could maintain adequate room air motion at low volumetric air flow rates, led to expanded use of VAV systems (Chen and Demster, 1995).

"In the early 1970s, the first installation of a VAV system was implemented in the Manhattan area of New York" (Rickelton and Becker, 1972). Terminal units were used to condition building interior zones, while exterior zone loads were handled by induction systems. "By 1972, VAV installations for individual projects in the United States served an aggregate total of over 10 million square feet" (Rickelton and Becker, 1972). Around this time, the first documented standards for VAV terminal boxes were also developed.

The schematic diagram of a single-duct variable-volume pressure-dependent terminal box without reheat is shown in Figure 4. The system consists of a controller, a thermostat, an actuator and a modulation damper. A modulation damper has a minimum damper position (e.g., 30\% open) for ventilation. This is often achieved by installing a mechanical pin to block movement of the damper to smaller angles, $\alpha$, as shown in Figure 4.

The single-duct variable-volume pressure-dependent terminal box has one control loop. As the temperature in the space drops below the set point, the damper begins to close and reduce the flow rate of air to the space. The damper is modulated to maintain the room air temperature set point between a fixed minimum damper position and the maximum damper position. 
In the pressure-dependent terminal box, the minimum air flow rate is controlled by the minimum damper position, which is often set at $40 \%$ open. It is commonly believed that the minimum air flow rate should be $30 \%$ of the design flow. This is based on the damper characteristics at constant entering air

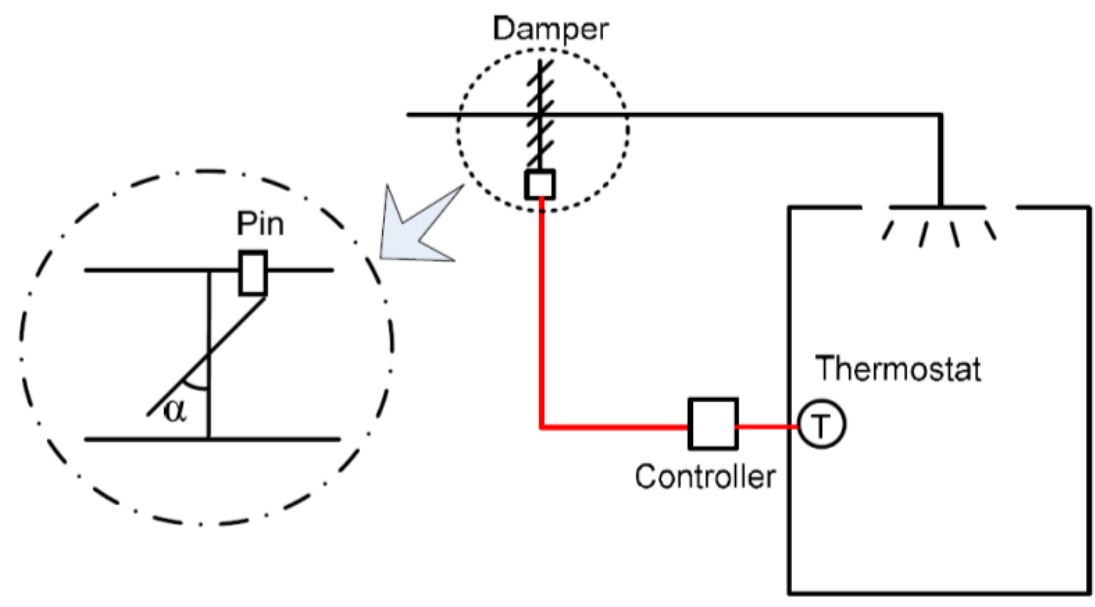

Figure 4 Schematic diagram of single-duct variable-volume pressure-dependent terminal box without reheat

pressure. The actual pressure at the entrance to the terminal box depends on several factors (e.g., the strategy used for control of the air-handler fan, the location of the specific terminal box in the distribution duct network, the terminal box damper position, and other factors) and is often significantly higher at partial loads than that under full load conditions. Excessively high entering air pressure at the terminal box entrance, often causes actual minimum air flow rates to exceed the design minimum air flow rate.

Single-duct variable-volume pressure-dependent terminal boxes without reheat have low initial costs and lower energy costs than boxes with reheat. They also use less reheat energy and fan power than constant air volume terminal boxes. The relationship between air flow rate and damper position changes as the static pressure at the entrance to the terminal varies, making use of the damper position as a predictor of flow rate impractical. A minimum air flow rate for ventilation that is too low may cause indoor-air quality issues. Poor control of the minimum air flow rate also leads to cold complaints by occupants because reheat is not available in these terminal boxes.

To solve the cold issue, the temperature of the supply air from the air handler can be increased, but this can cause high humidity in conditioned areas.

\subsubsection{Single-duct VAV pressure-independent terminal boxes without reheat}

A schematic diagram of a single-duct variable-volume pressure-dependent terminal box without reheat is shown in Figure 5. These systems consist of a controller, a thermostat, an actuator, a damper and a heating coil. 
The single-duct variable-volume pressure-dependent terminal box with reheat has one control loop with two sequenced controlled devices (the terminal box damper and the heating coil valve). During cooling, the damper begins to close and reduce the flow of air to the space when the temperature in the space

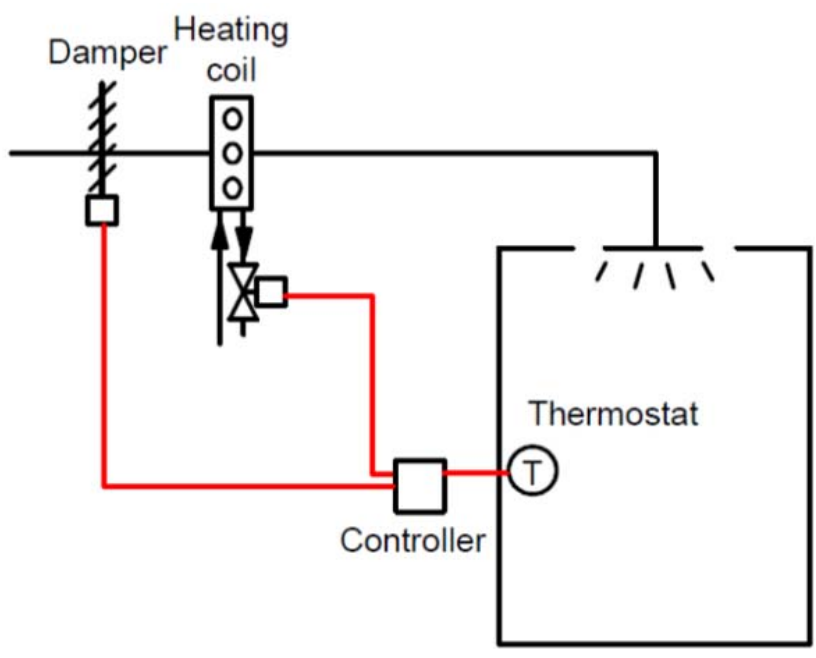

Figure 5 Schematic diagram of a single-duct variable-volume pressure-dependent terminal box with reheat

drops below the set point. When the damper reaches the minimum limit, the valve on the reheat coil begins to open and modulate the valve to maintain the room air temperature set point.

The single-duct variable-volume pressure-dependent terminal box with reheat can maintain the room temperature set point by modulating the reheating coil during heating requirement conditions. If the minimum damper position is too high, it can have large simultaneous heating and cooling and waste heating energy and fan power. On the other hand, it may cause indoor air quality issues if the minimum damper position is too low. Also, it can present control issues like instability and frequent opening and closing of the damper because of a narrow control band. Most importantly, the damper position cannot guarantee the actual required air flow rate.

\subsubsection{Single-duct VAV pressure-independent terminal box with reheat}

In the 1980s and 1990s, a flow station was developed for use in controlling the air flow rate through terminal boxes, and DDC control was also added. The schematic diagram of the single-duct variablevolume pressure-independent terminal box with reheat is shown in Figure 6. The system consists of a controller, a thermostat, an actuator, a damper, a heating coil and a flow station.

As the room temperature changes, the flow station controls the damper to maintain the set flow rate requirement within a range between maximum and minimum flow rate for the specific terminal box. The flow rate is modulated to ensure adequate, but not excessive, cooling of the zone served by the box. When the minimum air flow rate is reached and the cooling provided to the room is too large, the 
reheat coil is modulated open to increase the temperature of the air discharged to the zone as the means to maintain the room at a comfortable temperature. The maximum air flow rate is determined by the maximum sensible load of the zone and the supply-air and room-air temperature set points. The

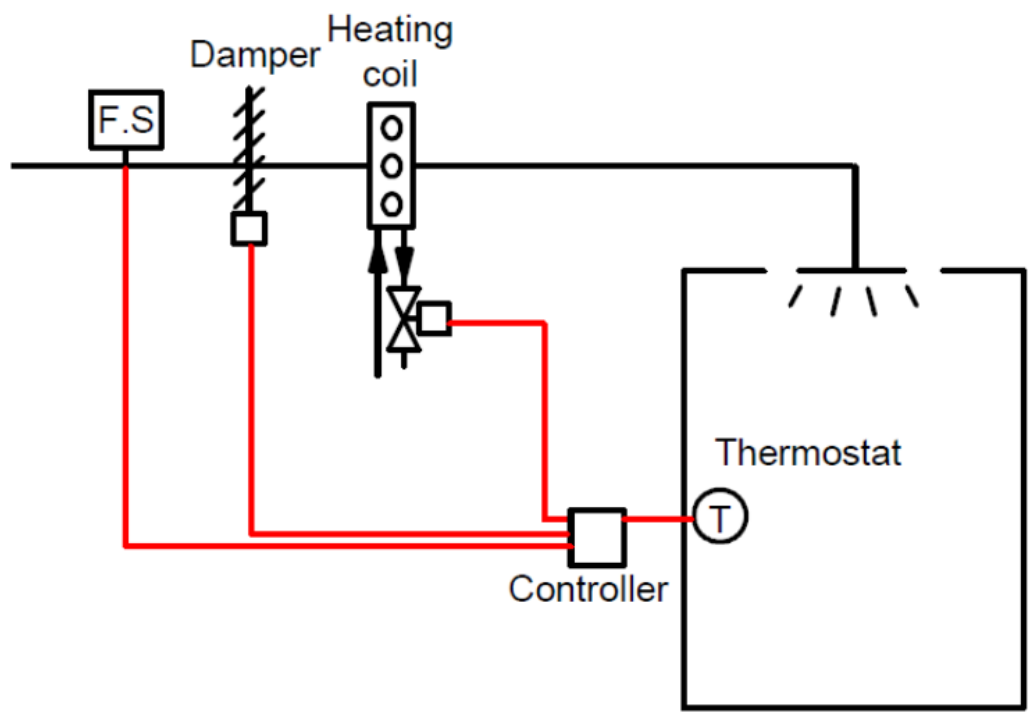

Figure 6 Schematic diagram of single-duct variable-volume pressure-independent terminal box with reheat

minimum air flow rate is determined by the ventilation requirement or maximum heating load requirement of the zone.

Through the use of a flow station, the single-duct variable-volume pressure- independent terminal box with reheat supplies air to the conditioned space, effectively maintaining the room temperature at its set point. The DDC controller allows for the implementation of more advanced control sequences than pneumatic control, but without an accurate air flow measurement, it could not be used effectively. Avery (1989) introduced the pressure-independent VAV box control. He explained that pressureindependent controls are a necessity for reheat type terminal boxes. But, velocity pressure is too low for reliable operation of the velocity controller when the unit is in the reheat mode. Stein (2005) also concluded that accurate flow measurements are necessary for proper control at low minimum air flow rate conditions.

\subsection{Minimum air flow rate settings for terminal boxes}

A fixed minimum air flow rate is used in conventional terminal box control sequences, which can cause occupant discomfort or excessive energy use. If the minimum air flow rate is higher than required to meet the zone load, unnecessary reheating of the air cooled by the air handler will occur, and the AHU will consume more fan power than necessary (Zhu et al. 2000, Taylor and Stein 2004). For VAV boxes with reheat, the minimum air flow rate, $V_{\min }$, is typically selected to be the largest of the following (Taylor and Stein 2004): 
- The air flow rate required to meet the design heating load at a supply-air temperature that is not too warm [i.e., not greater than about $90^{\circ} \mathrm{F}\left(32^{\circ} \mathrm{C}\right)$ ] -- Warmer temperatures tend to result in poor temperature control caused by stratification in the zone and short circuiting of air from diffusers where air enters the space to return-air grills.

- The airflow required to prevent poor air mixing -- This limit depends on the diffuser style and sizing. Thirty percent of the maximum cooling air flow rate $\left(V_{\max }\right)$ is a common rule-ofthumb, but some research (Bauman et al. 1995) has shown that lower rates are satisfactory.

- The minimum air flow rate required for ventilation -- The value depends on the applicable local code. In some cases, determining this rate can be simple [e.g., for California's Title 24 (CEC 2008)], or it can be complex because varying supply-air flow rates and outdoor-air fractions must be taken into consideration [e.g., for ANSI/ASHRAE Standard 62 (ANSI/ASHRAE 2007)].

The selection establishes the minimum value of $V_{\text {min }}$.

To minimize reheat energy losses, $V_{\text {min }}$ should not exceed the value specified by energy codes. Both California Title 24 (CEC 2008) and ASHRAE Standard 90.1 (ANSI/ASHRAE/IESNA 2007) limit $V_{\min }$ to the largest of:

- $30 \%$ of $V_{\text {max }}$, the maximum design air flow rate;

- $0.4 \mathrm{cfm} / \mathrm{ft}^{2}\left(2 \mathrm{~L} / \mathrm{s}\right.$ per $\left.\mathrm{m}^{2}\right)$ of conditioned floor area of the zone; and

- $300 \mathrm{cfm}(142 \mathrm{~L} / \mathrm{s})$.

This approach, which is widely used, establishes the maximum value of $V_{\min }$. Based on field experience (Cho and Liu 2008, 2009, Liwerant 2008), 30\% or more of $\mathrm{V}_{\max }$ is still very commonly used in current HVAC systems. The limit of $0.4 \mathrm{cfm} / \mathrm{ft}^{2}$ for the air-conditioned floor area is also undesirably high but a commonly selected value. If the zone served by the box has a low heating load but a large area, the air flow rate determined this way may be too high. Finally, even the value of $300 \mathrm{cfm}$ (the third option) is not the optimal value either it was originally derived from calculations for zones requiring special thermal considerations, such as a small zone with a high heating load or a space with north facing glass windows. Still, some engineers apply $300 \mathrm{cfm}$ as a standard practice for every space, regardless of the thermal conditions (Liwerant 2008).

In many buildings, engineers are responsible for specifying control parameters for a large number of terminal boxes with considerably different load conditions. Faced with constraints on the time used for specification and design, many HVAC designers employ these common methods instead of analyzing each box individually.

The ASHRAE standard for thermal comfort conditions (ASHRAE 1992) gives limits for the vertical air temperature difference. The air temperature of an enclosed space generally increases from floor to ceiling. If this difference is sufficiently large, occupants may feel localized head and/or foot thermal 
discomfort. To prevent such discomfort, the air temperature difference between measurements at heights of 4 inches $(0.1 \mathrm{~m})$ and 67 inches $(1.7 \mathrm{~m})$ should not exceed $5.4^{\circ} \mathrm{F}\left(3^{\circ} \mathrm{C}\right)$ (ASHRAE 1992).

Common methods provide a simple and easy way to determine the minimum air flow rate set point. However, these rely on the conventional fixed minimum air flow rate set points that may result in thermal discomfort or energy waste compared to a minimum rate that would depend on the occupancy of indoor spaces. As a result, many investigations have explored control strategies for improving the performance of VAV terminal controllers; descriptions of representative examples follow.

Fan-powered terminal boxes were developed to maintain high room air circulation at low load conditions through the use of only one small fan integrated into the terminal box. These terminal boxes reduce the reheating energy required compared to that required by boxes without fans by using plenum air, recirculating air from an over-ventilated zone, and shutting off the main AHUs. As a result, use of fan-powered boxes can reduce operating costs (Cho 2009). However, the retrofit and maintenance costs of fan-powered boxes are much higher than for VAV terminal boxes.

Stein (2005) suggested the dual-maximum-control sequence. As the load changes from full cooling to full heating, first the air flow rate set point is reset from its maximum value to its minimum, then the set point for the supply-air temperature is reset from its minimum to its maximum. Zhu et al. (2000) developed an operation and control strategy for terminal boxes with the air flow rate set point reset to improve building comfort and energy efficiency during the unoccupied and lightly occupied hours. Their method maintains zone temperatures at comfortable levels with daytime set points during unoccupied or lightly occupied hours, which decreases heating energy, cooling energy and fan power use significantly. This practice can be extended to normal operation hours for spaces that are unoccupied or lightly occupied at times by using an appropriate control sequence (Liu et al. 2002).

\subsection{Limitations of conventional control}

All of these control methods still cannot completely solve the challenges of varying occupancy in commercial building zones with time. Occupancy also varies dynamically because of meetings, business travel, staff termination, and office relocation. Many spaces that traditionally use large amounts of energy, such as conference rooms, training rooms and auditoriums are not fully occupied all the time, and the minimum air flow rate set points for these spaces are still maintained for full occupancy no matter whether 3 people or 30 people are in the room; when the room is lightly occupied this variation can result in significant occupant discomfort and energy waste.

Liu and Brambley (2011) presented some examples of common problems with conventional minimum air flow settings.

- Example 1: The minimum air flow rate set point is much higher than necessary for interior zones. As a result, the damper of pressure-independent terminal boxes opens more than necessary to meet the design minimum flow rate, introducing more cold air than needed into the space even though the zone cooling temperature set point is satisfied or exceeded. This causes overcooling and occupant discomfort. Under these conditions, some occupants will use 
portable foot heaters, even during summertime. Furthermore, some occupants may try to block the diffuser (e.g., using cardboard) to mitigate the cold draft.

- Example 2: The reheat valves are opened during the summer for exterior zone terminal boxes to compensate for a high minimum air flow rate setting. This causes excessive reheating to compensate for the oversupply of cooling, plus greater than necessary fan power consumption.

- Example 3: The actual building occupancy differs from the assumed design occupancy. For example, the occupancy of a conference room can vary throughout the day and from day to day. It is very common for a conference room with a capacity of 30 people to be used at times for meetings by only 2 or 3 people and to even be completely unoccupied at times. Under these conditions, the conference room can be very cold because the minimum air flow rate is set high to meet the ventilation requirements for the designed occupancy. No occupancy information is used to control terminal boxes, resulting in both uncomfortably cold occupants and wasted energy for cooling and fan operation. In fact, the air flow rate required for design occupancy is often supplied even when conference rooms are unoccupied (when no ventilation is needed), because terminal box controls do not commonly use occupancy (e.g., motion detecting) sensors to detect the presence and absence of occupants.

- Example 4: The actual occupancy in areas of a building change over time as space uses are changed. For example, an office might be converted to a storage room, or the number of occupants of an open plan office space may change significantly because a company downsizes or several staff are out of the office traveling. The minimum air flow rate set point could be adjusted to conform to occupancy changes. Energy is wasted when air is provided at the same flow rate when the office is unoccupied as when it is half occupied or fully occupied.

These issues represent real challenges in the daily operation of a commercial building. From the previous conventional solutions, the research opportunities are identified. Common practice uses simple and easy-to-implement methods to determine the minimum air flow rate; however, a fixed minimum air flow rate cannot adequately meet variable zone load conditions. System upgrades could address these problems. For a new building, the selection of fan-powered boxes is a good way to get the benefits; however, retrofits to existing buildings are costly. As a result, methods for improving the (energy, cost, and comfort) performance of existing terminal boxes without replacing them could be productive.

\subsection{Summary of Section 3}

All of the terminal box designs and control methods described in this section still do not completely solve the challenges of varying occupancy in commercial building zones. The commercial real estate occupancy rate can vary frequently. Occupancy also varies dynamically because of meetings, traveling, staff termination, office relocation and even the daily use patterns of occupants. Many spaces that traditionally use large amounts of energy, such as conference rooms, training rooms and auditoriums, are not fully occupied continuously, and the minimum air flow rate set points for these spaces are still 
maintained for full occupancy no matter whether 5 people are in the room or 50, which when the room is lightly occupied, results in significant occupant discomfort and energy waste. 


\section{Sensors for occupancy-based control (OBC)}

Stanke (2010) proposed potential outdoor-air (OA) intake rate reset approaches for air handlers for multi-zone systems. One of his approaches involves continuously counting the occupants in a zone with an appropriate sensor and solving Equation (3) to determine the outdoor-air intake flow rate set point needed to provide adequate ventilation for the occupants. This approach can be extended to dynamically resetting the set point for the minimum air flow rate for terminal boxes based on sensing the number of occupants to improve their energy efficiency and the level of comfort provided for occupants. Building occupancy sensors are under development that can count the number of occupants in each room. This data could be delivered to a building automation system or directly to a terminal box controller to provide occupancy-based ventilation to each zone.

\subsection{Sensor technologies}

A building occupancy number sensor is the key to controlling the ventilation supplied to zones based on zone occupancy. Many situations exist where it is useful or essential to count people, and numerous

automated people-counting systems have been developed over the years. Several kinds of counters that require contact with people, such as turnstiles, are used because contact-type counters count very accurately. These counters, however, cannot be applied to spaces within commercial buildings because, except at a few critical places (e.g., entrances), they obstruct the normal flow of people in work spaces and would require installation for each room. Mat-type switches, another type of contact counter, are not durable enough to withstand the repetitive foot stresses of high traffic areas (Hasinmoto et al. 1997a, b; Yoshiike et al. 1999; Yoshinaga et al. 2010).

Most commercially available non-contact occupant counters use infrared beams or ultrasonic sensors. Other specialized human information sensors have also been developed for counting occupants (Amin et al. 2008). Several kinds of sensors currently can provide information on occupancy, such as video cameras equipped with people-counting software, optical tripwires and pyroelectric infrared (PIR) motion sensors that count the number of people crossing a particular area, and sensors that measure the concentration of $\mathrm{CO}_{2}$ in a space. Brief discussions of available technologies follow.

Carbon dioxide sensors provide concentration readings in parts per million (ppm), which are indicative of the occupancy of a space. However, reliably correlating $\mathrm{CO}_{2}$ levels with actual occupancy is difficult because of the high variability of readings and slow response time of $\mathrm{CO}_{2}$ sensors. It also takes time for the $\mathrm{CO}_{2}$ concentration in a room to build up. Variability arises from fluctuations in ambient $\mathrm{CO}_{2}$ levels, HVAC system control, and the frequency of opening and closing of doors. Furthermore, $\mathrm{CO}_{2}$ measurements suffer from slow response time (Meyn et al. 2009). For example, the inevitable delay in $\mathrm{CO}_{2}$ concentration following an increase in occupancy is at least 10 to 20 minutes. The sensor location is another important factor.

Motion detection based on PIR provides an indication of motion within the sensor (distance) range. By using them in pairs, PIR detectors can be used to determine the direction of motion, e.g., a person entering or leaving a room through a doorway. PIR detectors, however, have limitations for this application. First, the sensor range is limited, and individual PIR sensors are not good for monitoring 
large spaces. Second, multiple people passing a PIR sensor (e.g., in a doorway) at the same time may be undercounted.

Video cameras can provide information regarding people count and their direction of flow. These cameras if not properly installed and configured, can exhibit significant errors, arising from three main factors. First, video sensors are affected by lighting conditions. Low light levels can lead to single persons being counted multiple times. Also, turning a light switch on or off may trigger a sensor count. Second, multiple people crossing the field of view at the same time may be undercounted. Last, the video system may count several crossings at times when occupants loiter in the camera's field of view. Such events can lead to a significant positive bias (Hashimoto et al. 1997a, 1997b, 1998, 2000; Meyn et al. 2009).

\subsubsection{Smart camera object position estimation system (SCOPES)}

Kamthe et al. (2009) developed the SCOPES system, a wireless camera sensor network for gathering traces of human mobility patterns in buildings. The claimed accuracy is $80 \%$ of events counted correctly. A disadvantage with visual counting systems is their high cost. Other critical drawbacks include poor accuracy caused by difficulty in recognizing occupants whose clothing color is close to the background color and ambient lighting interference (Hashimoto et al. 1997a , 1997b; Yoshiike et al. 1999; Yoshinaga et al. 2010). SCOPES also has a shorter lifetime and higher power consumption than thermal imaging systems.

\subsubsection{Thermal image systems using thermal array detectors}

Hashimoto et al. (1996, 1997a, 1997b, 1998, 2000) developed a people-counting system that consists of a one-dimensional eight-element array detector made from pyroelectric $\mathrm{PbTiO}_{3}$ ceramics, an infrared (IR) transparent spherical lens and a cylindrical mechanical chopper. This compact sensor is set at the top of a doorway with the element array parallel to the direction of movement of people through the doorway. The sensor, mounted on the ceiling detects infrared radiation from the floor except when people pass through the doorway, changing the radiation incident of the detector and the signal output from the detector elements. Thus, the number of people passing in each direction through the doorway can be obtained by processing the detector output. This system can detect the net flow of people through a 1-meter wide doorway (2.2-meter height) with more than 98\% accuracy (Hashimoto et al. 1996, 1997a, 1997b). The number of people passing by a 2-meter wide door can be detected with more than 95\% accuracy (Hashimoto et al. 1998). Errors are caused by large movements of the arms or legs (e.g., gesturing). The detection accuracy can be improved by higher sensor spatial resolution (e.g., by adding elements to the sensor) and better matching the area viewed to individual sensor elements.

A human information sensor with an umbrella-shaped chopper and an array detector made from pyroelectric ceramic was developed by Yoshiike et al. (1999). A rotating array detector mechanism allows the sensors to have wide views (10-m diameters). With the human detection algorithm, data on occupancy can be detected with $97 \%$ accuracy (in 389 samples). 
Amin et al. (2008) developed a system for counting people in a scene using a combination of low-cost, low-resolution visual and infrared cameras. The results of 18 experiments show that the maximum error percentage is within $3 \%$ over a wide range of lighting conditions.

\subsection{Example of a pyroelectric sensor}

The pyroelectric sensor can be used in the people counting application with a pair of pyroelectric infrared radial (PIR) sensors or an array of PIR sensors in a doorway. Commercial products of this type are currently available for retail store customer counting.

\subsubsection{Theory and example}

The PIR sensor is used to detect thermal radiation from the human body in the wavelength range $8 \mu \mathrm{m}$ to approximately $14 \mu \mathrm{m}$ ). PIR sensors have lower costs than video cameras, and their sensitivity to angular velocities is from 0.1 to $3 \mathrm{rad} / \mathrm{s}$.

When a PIR sensor is initially powered on, the sensor takes approximately 30 seconds of warm-up time to respond to its environment. During this time, there should be little or no movement in the environment viewed by the sensor. The sensor takes the average temperature in its detection range and saves this value in a memory location on the sensor; this requires that the system is turned on before people begin entering and leaving the monitored room, if the sensor is part of a system for detecting room occupancy. The warm-up time is critical because it establishes a baseline for the environment thermal background. The system starts the passive infrared sensors before turning on any of the other components. In addition, this warm-up time requires the room occupancy system to already be turned on before people begin entering and leaving the monitored room.

Passive infrared sensors can serve as the eyes through which we observe a room or entrance to a room. A passive infrared occupancy sensor has two slits through which thermal radiation is received. A differential in temperature can be detected that corresponds to a difference in the thermal radiation fields viewed through the two slits. Whenever a person passes a passive infrared sensor, as shown in Figure 7, thermal radiation from the person causes the sensor to produce a signal pulse, which corresponds to the temperature difference between the two slits. The change in the amount of infrared radiation striking the element changes the voltages generated, which are measured by an on-board amplifier. The infrared signals change rapidly as a person walks by the sensor causing the on-board amplifier to trip the output to indicate motion. However, when the sensor is idle and nothing is detected, the same amount of infrared energy passes through the two slits so the difference in electrical potential is zero, and no movement is detected. The passive infrared sensors used in this application do not measure or distinguish between the magnitudes of the temperature differences, but rather indicate that a temperature change exists. As a result, the passive infrared sensor outputs a high or low digital signal to indicate when a motion has been detected. The output of the passive infrared sensor is then sent to the transmitter on the printed circuit board and eventually, wirelessly, to a microcontroller to be processed. 


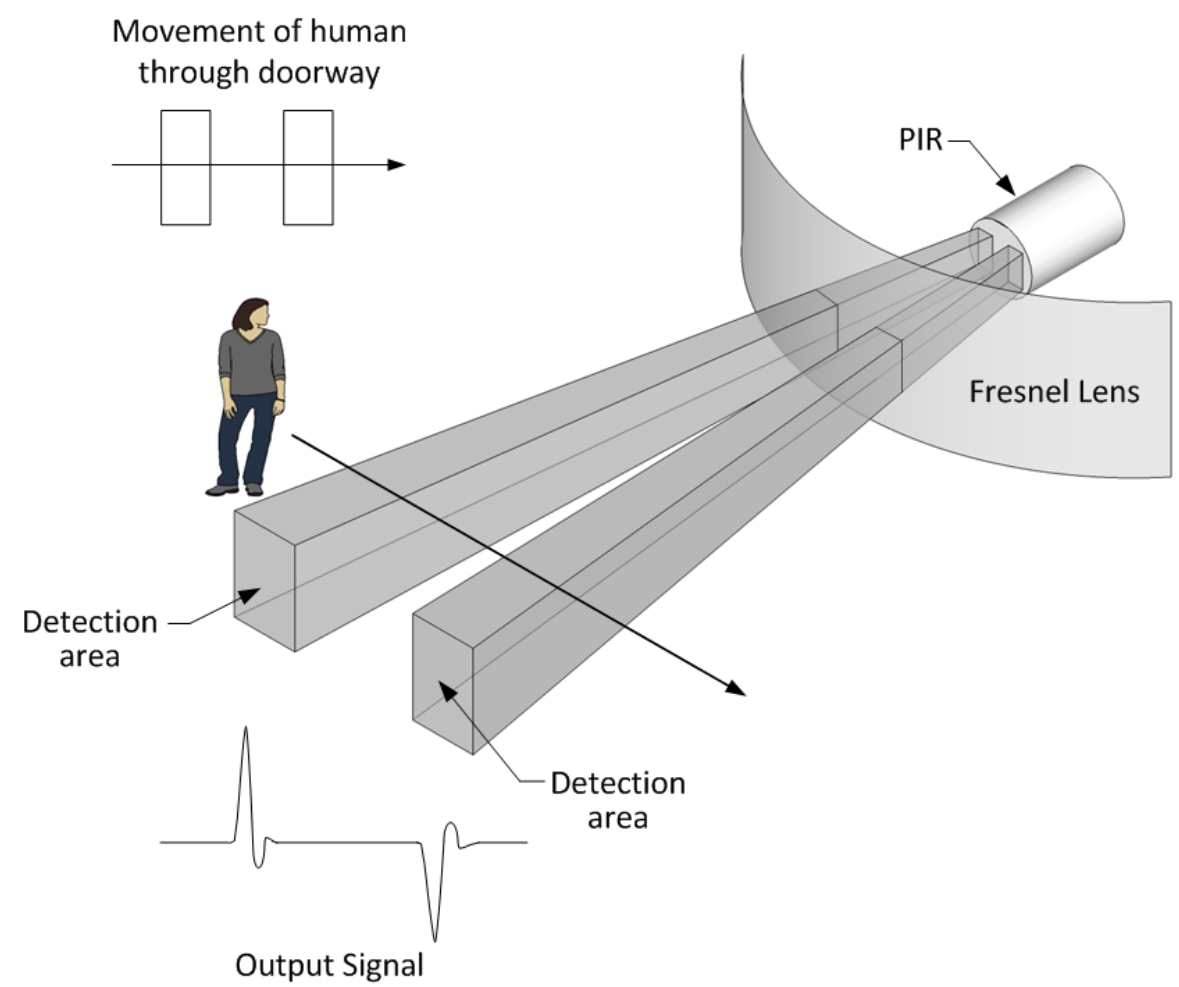

Figure 7 Theory of passive infrared sensors

Two sensors are needed in a doorway to detect the direction of occupancy movement. The result is a sensor system that can count the net number of people entering a room. The first passive infrared sensor encountered when a person enters the room through the doorway PIR-1. The second sensor encountered when entering is considered PIR-2. The microcontroller observes which passive infrared sensor has detected movement first. If the microcontroller receives the information that PIR-1 detects movement before PIR-2, then the microcontroller interprets the order of events and identifies the event as someone entering the room. Once PIR-2 detects motion, the microcontroller knows that someone has fully entered the room, and the room occupancy count is incremented by one. Utilizing light emitting diodes (LEDs) helps display the order of events or the order of triggering among the passive infrared sensors. Once someone has fully entered the room, the microcontroller waits for both sensors to return a low state signal (i.e., output a low voltage). Then the microcontroller is ready to count the next person entering or leaving the room. A similar procedure is used to detect when someone is walking out of the room, except the order in which the sensors detect motion is reversed, and the room occupancy counter decrements instead of incrementing.

Multi-element, two-dimensional pyroelectric arrays used in thermal imaging systems usually include a mechanical chopper system for modulating the infrared radiation from a scene. The signals from the various elements of the array are read out in phase with the chopper in a serial raster scan fashion, and subsequently processed to produce an image that is compatible with normal video standards. 


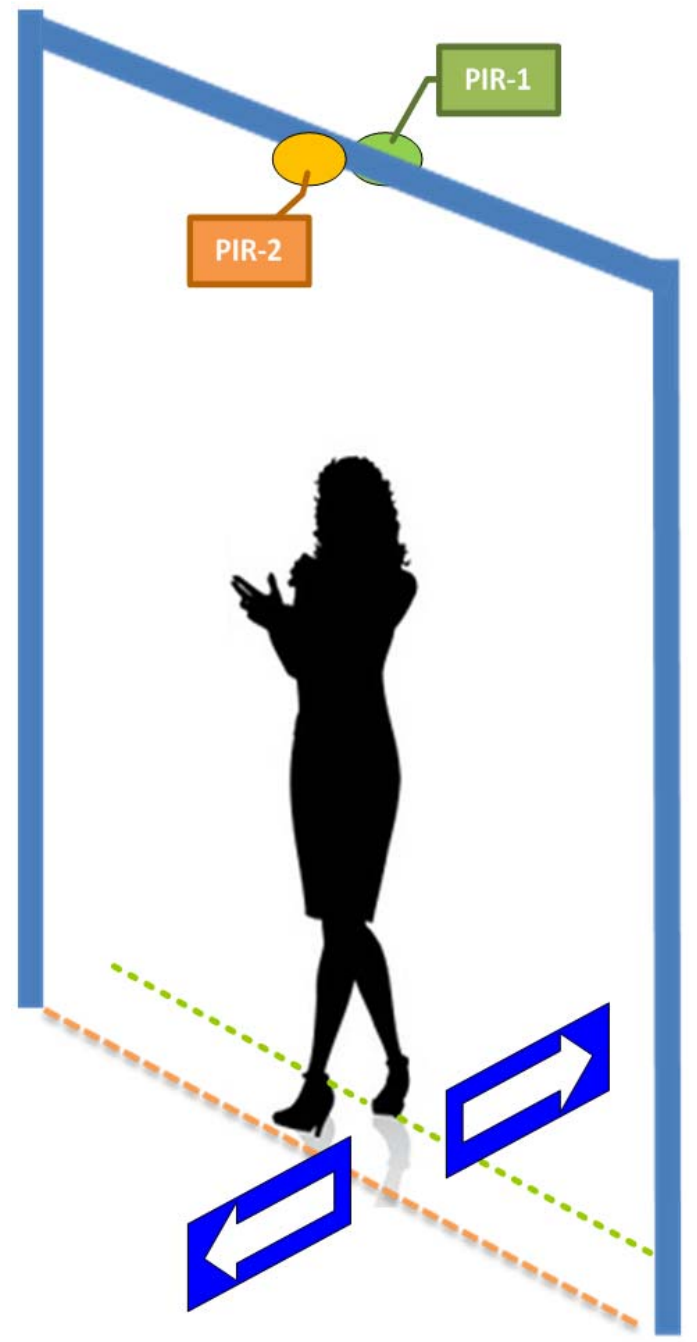

Figure 8 Example of detecting direction of occupant motion

\subsubsection{Commercial products}

The system from Infrared Integrated Systems Ltd. (Irisys) is an example of a commercial people-counting system for retail stores and other public buildings. The Irisys Thermal Imaging People Counter family of sensors is intended for a wide range of people counting, sensing and detection applications.

The units detect infrared radiation, each containing a 16x16 array of passive infrared (PIR) sensors. They are ideally used in a downward viewing position, with an unhindered view of the target area. The unit functions optically, "seeing" the emitted thermal radiation as long wavelength light, through a germanium lens with a $60^{\circ}$ field of view. The principle of operation may be visualized as a square pyramid with a $60^{\circ}$ apex. The sensing area is a square on the floor having a width approximately equal to the sensor mounting height; i.e., at $3.5 \mathrm{~m}$, the unit "sees" a $3.5-\mathrm{m} \times 3.5-\mathrm{m}$ square on the floor. It 
cannot see through glass or any other solid material that is opaque to infrared radiation (many materials that are transparent to visible light are opaque to infrared radiation).

A virtual counting-line is defined in the scene by the operator using a set-up tool, usually a palm-top PC, and counting occurs when people passing through the scene cross the counting line in a defined direction. Mounting height ranges from 2.5 to $4.5 \mathrm{~m}$ and can be accommodated with the standard lens; other lenses are available to cover greater mounting heights. No calibration or scene-specific set-up is required; the unit is mounted and is immediately functional. The units may be used as single counting nodes, linked into networks of up to 30 units, or configured to span a wide opening (e.g., a wide doorway). In the wide opening mode, up to eight units are linked to span the opening and appear to the user system as a single counter unit with a wide footprint. The wide opening mode contains intelligence that prevents possible multiple counting at the interface between adjacent units (Irisys 2012).

The Irisys and other commercial products are not widely installed in office buildings because of their high software cost.

\subsection{Other occupancy sensor technology under development}

The Energy Dynamics Laboratory (EDL) in Logan, Utah, is developing an integrated occupancy sensing system designed by leveraging existing low cost and widely available micro-controllers, CMOS Imaging sensing (CIS) chips along with low bandwidth and low cost wireless ZigBee (Zigbee Standards Organization 2007, Hendrix and Kohl 2009) chips for communications. These elements are integrated into a small form factor that is compatible with standard metal electrical junction boxes used in all buildings in the U.S. The progress made by EDL could eliminate the complex process for installation and commissioning required for today's PIR, ultrasonic, and $\mathrm{CO}_{2}$ sensors.

The CMOS imaging sensors are capable of being self-powered, operational in the microwatt range of power, and truly plug-and-play through self-learning and self-commissioning firmware.

\subsection{Technical challenges and research gaps for occupancy sensors}

The major challenges and research gaps include:

- $\quad$ Software and algorithms for accurate people counting does not exist in low-cost embedded microprocessor systems. Solutions available commercially today are relatively expensive (hundreds to low thousands of US dollars per hardware unit) and make the energy savings return on investment (ROI) decades for occupancy-sensing based VAV control applications . The key challenge is the redesign of computer vision and machine-learning algorithms to have a significantly lower order of computational complexity. A reduced computational complexity will allow porting of these algorithms onto some of the lowest-cost embedded micro-controllers available on the market (single digit dollar costs in high volumes). 
- $\quad$ Reducing the cost of initial commissioning of occupancy detection systems will require progress towards full automation of the process and learning capabilities.

- Research is needed to create algorithms that learn features of rooms such as entry and exit points of cubicle farms, narrow types of rooms such as corridors, automatic detection and characterization of windows, automatic adjustment of parameters to various types of activities, differentiation between machines and humans, differentiation between reflections of occupants and occupants themselves, and coordination across multiple sensors and third party platforms to enable building automation systems to make better decisions on HVAC control, lighting control, etc.

- Algorithms will require testing, modification, and enhancement to operate in a wide range of room types, including rooms with floor-to-ceiling windows, flooring material and objects that produce reflections, furniture such as tall shelves and storage racks that can produce occlusion effects, and large numbers of flickering lights such as light emitting diodes (LEDs) on racks of computer and network equipment. Furthermore, solutions are needed for rooms with very high ceilings, rooms in which machines (such as forklifts) move just as easily as humans, and rooms with very low lighting.

- As constraints increase as systems are moved to smaller hardware platforms, the design or software and firmware to implement efficient, low-complexity algorithms will present programming challenges.

- Constraints associated with small amounts of on-chip memory buffering will present a challenge to the shelf life of buffering data from imaging sensors. This will present challenges for the design of tiny memory-based algorithms and firmware.

\subsection{Summary of Section 4}

Key to occupancy based control for terminal boxes is a technology for sensing the actual number occupancy of building zones in real time. Several technologies show promise, especially pyroelectric sensor arrays, which are presently implemented in retail stores and some other public buildings. Thermal imaging arrays using pyroelectric sensors can provide fairly accurate counting results and perform well at various lighting levels. No current occupancy number sensing technology, however, currently fully meets the need of sufficiently low total cost, although one technology under development shows promise and is beginning to approach the appropriate cost. Key remaining challenges to achieve a practical occupancy number sensing technology for HVAC control include: advancements in computer vision and machine learning that significantly reduce computational 
complexity and enable porting of software to the lowest-cost microprocessor platforms; full automation of occupancy sensor commissioning to reduce installation/commissioning costs; algorithms that learn features of rooms and adapt to meet the specific constraints of each individual room. Low cost represents the overarching requirement for a practical occupancy number sensing system for control; all technical advancements must be achieved subject to this constraint. 


\section{Demand controlled ventilation}

Ventilation systems are designed to provide a minimum level of outdoor air based on the designed occupancy of the spaces served. DCV is defined as ventilation that automatically adjusts based on the occupancy of the space served. Therefore, DCV reduces outdoor-air intake rates below design rates when the actual occupancy of spaces served by the system is less than design occupancy (ANSI/ASHRAE/IESNA 2010). It includes hardware, software, and a control strategy, and is an integral part of a building's ventilation design (Stipe 2003). The concept of automatic ventilation control based on occupant demand has been recognized as an energy efficiency measure for nearly 30 years. Commonly used methods for assessing zone population include time-of-use schedule, occupancy sensors, and $\mathrm{CO}_{2}$ sensors. The International Energy Agency (IEA) Annex 18 project (1987-1992) published six reports related to DCV covering review of the state of the art, a sensor market survey, a sensor test, case studies, and a source book (Raatschen 1990, 1991; Fahlen and Andersson 1992; Mansson and Svennberg 1992; Mansson 1992). Emmerich and Persily (2001) comprehensively reviewed the literature on $\mathrm{CO}_{2}$-based demand-controlled ventilation working from their previous review (Emmerich and Persily 1997). Topics reviewed include field demonstration projects, computer simulation studies, studies of sensor performance and location, regulatory and standard requirements, and applications of the approach. This section of the report summarizes finding from those previous literature reviews. The intent is to identify the research gaps, especially those focused on the application of DCV to multi-zone VAV systems.

\section{$5.1 \mathrm{CO}_{2}$-based DCV}

Although population counting, $\mathrm{CO}_{2}$ sensors, timers, occupancy schedules and occupancy sensors are listed as acceptable ways to define the instantaneous occupancy by ANSI/ASHRAE (2010), $\mathrm{CO}_{2}$-based DCV is the most common design. Won and Yang (2005) reviewed sensors for DCV and recommended $\mathrm{CO}_{2}$ sensors based on three criteria: performance, cost, and IAQ. People consume oxygen and generate $\mathrm{CO}_{2}$ and odorous bioeffluents. The rates of $\mathrm{CO}_{2}$ and bioeffluent generation by a person primarily depend on body size and level of physical activity (ASHRAE 2009). Experimental studies showed that the two emission rates are proportional. Therefore, $\mathrm{CO}_{2}$ concentration has been considered a fairly dependable indicator of the concentration of odorous bioeffluents (ASHRAE 2010). Emmerich and Persily (2001) summarized that $\mathrm{CO}_{2}$-based $\mathrm{DCV}$ is most likely to be effective for buildings with the following features:

- The existence of unpredictable variations in occupancy

- A building and climate where heating or cooling is required for most of the year

- Low pollutant emissions from non-occupant sources.

Applications of $\mathrm{CO}_{2}$-based DCV to different system types are discussed separately below.

\subsection{1 $\mathrm{CO}_{2}$-based DCV for single-zone systems}

$\mathrm{CO}_{2}$-based DCV has been used in single-zone systems for many years. The primary method uses the $\mathrm{CO}_{2}$ concentration sensed at the zone level to control the outdoor-air intake rate. The control strategies are 
mostly developed for practical use, and they may or may not meet ventilation standards continuously. Figure 9 illustrates $\mathrm{CO}_{2}$-based DCV control schematically for single-zone systems.

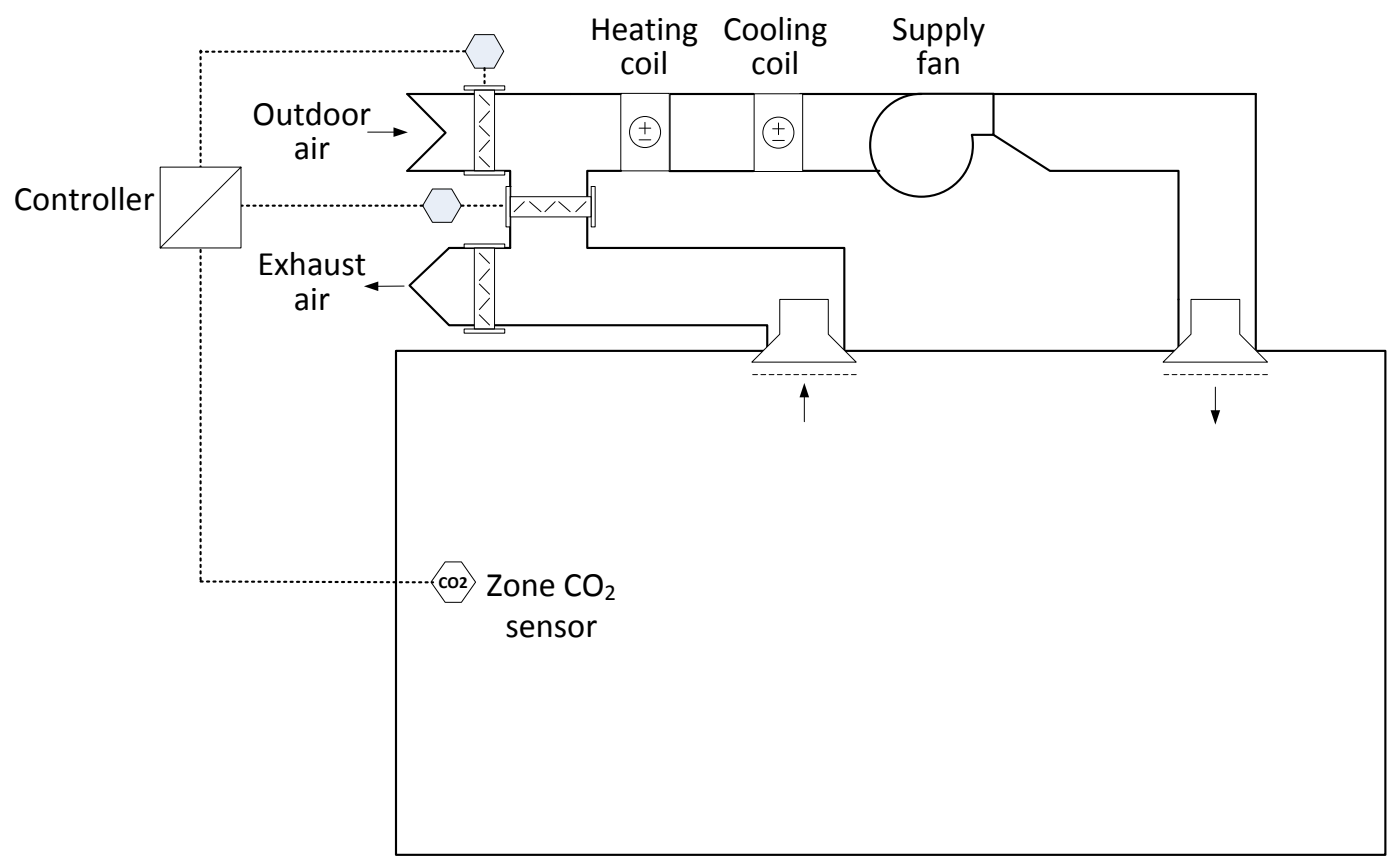

Figure $9 \mathrm{CO}_{2}$-based DCV control schematic for single-zone systems

Houghton (1995) describes a few strategies including a simple $\mathrm{CO}_{2}$ set point control of the OA damper to fully open and fully closed positions, proportional control in which the OA damper is opened in proportion to the $\mathrm{CO}_{2}$ concentration, and proportional, integral, derivative (PID) control, which considers the rate of change in $\mathrm{CO}_{2}$ concentration in addition to the concentration itself. Schell et al. (1998) and Schell and Inthout (2001) discuss DCV control strategies in more detail (including set points and proportional, exponential and PID control), models for selection of DCV strategies, and benefits of DCV.

After Standard 62.1-2004 (ANSI/ASHRAE 2004) was published (in which ventilation requirements became dependent on both zone area and occupancy), Stanke (2006) compared various control approaches including non- $\mathrm{CO}_{2}$-based DCV and concluded that the best choice depends on the HVAC system, the expected population profile for the zone, the cost of sensors, and the cost and desired sophistication of the controller. Taylor (2006) illustrated how the control system designs should be modified in response to the change in Standard 62.1. The relationship between $\mathrm{CO}_{2}$ concentration and air flow rate set point was established under the assumption of steady-state conditions. Therefore, for single-zone systems, the minimum required outdoor-air intake flow rate can be related to the difference between indoor and outdoor $\mathrm{CO}_{2}$ concentrations (Taylor 2006).

Recently, recognizing that steady-state conditions can hardly be reached in practice, for buildings with occupancy schedules that change hourly, such as a school gymnasium, Lu et al. (2011) developed a control strategy for these situations. This strategy is to supply a base ventilation rate during unoccupied periods and to supply a calculated ventilation rate during occupied hours by solving a $\mathrm{CO}_{2}$ mass balance 
equation, which was developed to maintain indoor $\mathrm{CO}_{2}$ concentration near its set point. The simulation results for an example DCV system with the new strategy showed an average ventilation rate reduction of $34 \%$ compared to the conventional proportional DCV control strategy.

\subsection{2 $\mathrm{CO}_{2}$-based DCV for multi-zone VAV systems}

Early studies in $\mathrm{CO}_{2}$-based DCV for multi-zone VAV systems were mostly done with simulations (Knoespel et al. 1991; Emmerich et al. 1994; Sorensen 1996). Sorensen (1996) modeled a two-zone office with one zone served by a CAV terminal box without DCV and the other by a VAV system with $\mathrm{CO}_{2}$-basd DCV. Both $\mathrm{CO}_{2}$ concentration and temperature were used to control the supply-fan speed and outdoor-air damper position. An upper limit of 900 ppm and a lower limit of 700 ppm for zone $\mathrm{CO}_{2}$ concentration were specified in the simulation model for the VAV system. When the $\mathrm{CO}_{2}$ concentration is above the upper limit, the damper position gradually opens by $1 \%$ at each simulation time step. After the damper is fully open, if the $\mathrm{CO}_{2}$ concentration is still above its upper limit, the supply-fan speed is gradually increased by $5 \%$ at each simulation time step. When the $\mathrm{CO}_{2}$ concentration is below the lower limit, the controller decreases the fan speed and outdoor-air damper position to save energy. Sorensen (1996) found energy savings of $31 \%$ for the VAV system compared to the CAV system without DCV for cold ambient conditions.

Nassif et al. (2005) and Nassif and Zaheer-uddin (2007) proposed a $\mathrm{CO}_{2}$-based DCV control strategy (S$\mathrm{CO}_{2}$-DCV) to maintain the supply-air $\mathrm{CO}_{2}$ concentration set point low enough to dilute $\mathrm{CO}_{2}$ generated in the critical zone sufficiently to meet occupant needs. The supply-air $\mathrm{CO}_{2}$ set point is determined assuming that the critical zone is fully occupied. This can lead to over-ventilation of other zones and even the critical zone, when it is not actually fully occupied. Over-ventilation though leads to low $\mathrm{CO}_{2}$ concentrations in the return air and consequently in the supply air. Detecting this, the system closes the air-handler outdoor-air damper until the supply-air $\mathrm{CO} 2$ concentration set point is reached, which reducing over-ventilation. A similar strategy was also reported by Warden (2004). Nassif et al. (2005) compared this strategy with four other strategies including a $\mathrm{CO}_{2}$-based DCV strategy that adjusts the outdoor-air intake rate using the monitored $\mathrm{CO}_{2}$ concentration measured in the main return-air duct to the air handler. They concluded that the $\mathrm{S}-\mathrm{CO}_{2}-\mathrm{DCV}$ strategy can dynamically reset the outdoor-air intake rate to be lower than the peak design flow rate, yet the dynamic supply-air flow rate is always higher than that for the $\mathrm{CO}_{2}$-based DCV system. The authors reported that the return duct $\mathrm{CO}_{2}$-based DCV did not provide enough ventilation to critical zones (i.e., zones requiring the most ventilation). In response to the new requirements in Standard 62.1-2010 (ASHRAE 2010), Nassif (2012) updated his S$\mathrm{CO}_{2}$-DCV method to meet the new standard.

Murphy (2005) described two control approaches, one using $\mathrm{CO}_{2}$-based DCV alone for a multi-zone VAV system and the other using $\mathrm{CO}_{2}$-based DCV combined with reset of the outdoor-air damper ventilation position. The first approach is costly because $\mathrm{CO}_{2}$ sensors are required in every zone. The building automation system (BAS) monitors all the sensors and controls the outdoor-air damper of the air handler to bring in outdoor air at a rate sufficient to satisfy the ventilation needs of the critical zone (all other zones are over-ventilated). The second method requires $\mathrm{CO}_{2}$ sensors to be installed only in densely occupied zones. The measured $\mathrm{CO}_{2}$ levels are used in real time to reset the zone ventilation 
requirements, which are then used in multi-zone ventilation calculations to reset the outdoor-air intake rate. This method does not use $\mathrm{CO}_{2}$ concentration measurements to control the terminal boxes.

GE-Sensing (2006) describes another sequence of operation for their DCV VAV system with reheat. When the zone $\mathrm{CO}_{2}$ concentration is greater than the set point, the damper is modulated open using a PID control loop. If the maximum damper position is reached and the $\mathrm{CO}_{2}$ concentration set point is still not met, the air handler outdoor-air damper for the system is modulated using a PID control loop. Although the approach suggested by PG\&E (2007) is slightly different, it also first modulates the terminal box dampers to control the rate of air flow into the zone and then the air-handler outdoor-air damper to change to outdoor-air intake of the system. Such a control approach is included in the User's Manual for Standard 62.1-2004 (ASHRAE 2004), but it was removed in the 2007 version of the user's manual (ASHRAE 2007) because it is largely unproven (Stanke 2010).

Several possible approaches for dynamic ventilation reset with and without DCV are briefly summarized by Stanke (2010). Occupancy sensing methods other than $\mathrm{CO}_{2}$ sensors are included in Stanke's study, and the advantages and disadvantages of each method of dynamic ventilation reset are given, but no single method emerges as the clear best solution. More research is needed to identify or develop the method that performs best for a variety of situations. An ongoing ASHRAE Research Project (RP-1547) on $\mathrm{CO}_{2}$-based DCV for multiple zone HVAC systems seeks to resolve some of these issues.

A model-based optimal ventilation control strategy for multi-zone VAV systems was proposed by Xu et al. (2009). This method uses genetic algorithms to seek an optimized solution for temperature set points of critical zones, while considering the dynamic changes in occupancy.

\subsection{Savings from DCV}

Many buildings now use DCV, and a wide range of savings have been reported. Mansson (1994) and Meier (1998) estimated energy cost savings from DCV for various types of buildings or spaces. The results show energy cost savings of $20 \%$ to $30 \%$ for open-space offices with average occupancies equal to $40 \%, 20 \%$ to $50 \%$ for restaurants and lecture halls, and up to $60 \%$ for assembly halls, theatres, cinema booking halls, airport check-in areas, and entrance halls. Sand (2004) reports from a literature review savings of $\$ 0.05 /$ sf to more than $\$ 1 /$ sf from use of DCV. Brambley et al. (2005) report on a market assessment for DCV in 2005; the energy impacts found for DCV are summarized in Table 1.

\subsection{Limitations of DCV}

Although $\mathrm{CO}_{2}$-based DCV has been accepted as an energy efficiency design solution, questions have been raised regarding the maintenance, calibration frequency, drift, temperature effects, and proper location of sensors. Sensor reliability is often identified (Jones et al. 1997; Fisk and De Almeida 1998; Fisk et al. 2007; Frank 2011) as a potential issue. If any of the sensors is out of calibration so that the measured $\mathrm{CO}_{2}$ concentration is higher than the true value, the system will bring excessive outdoor air into the air-handling system to meet the incorrect measured $\mathrm{CO}_{2}$ level for the zones served by the air handler. Houghton (1995) discussed the impact of free cooling by an economizer on DCV systems, noting that long periods of economizing decrease the potential energy savings from DCV. The 
relationship between DCV and economizer operation has not yet been fully addressed (Brandemuehl and Braun 1999).

Table 1 Summary of DCV energy savings (Brambley et al. 2005)

\begin{tabular}{|l|c|l|}
\hline Attribute & \multicolumn{1}{|c|}{ Value } & Notes \\
\hline Technical Market Size & $\begin{array}{c}\sim 5 \text { billion } \\
\mathrm{ft}^{2}\end{array}$ & Most conditioned commercial floor space \\
\hline $\begin{array}{l}\text { Relevant Annual Energy } \\
\text { Consumption }\end{array}$ & 5.4 quads & All HVAC energy \\
\hline Energy Savings & $10-15 \%$ & $\begin{array}{l}\text { Approximate average; large variations depending on } \\
\text { actual versus design occupancy level patterns, } \\
\text { building type, and climate }\end{array}$ \\
\hline $\begin{array}{l}\text { Technical Annual Energy } \\
\text { Savings Potential }\end{array}$ & 0.5 quads & $\begin{array}{l}\text { Approximate average; large variations depending on } \\
\text { Rectual versus design occupancy level patterns, } \\
\text { building type, and climate }\end{array}$ \\
\hline Simple Payback Period & $10-15 \%$ & $\begin{array}{l}\text { Can vary more depending on specific building } \\
\text { occupancy patterns. }\end{array}$ \\
\hline Ultimate Market Penetration & $15-30 \%$ & For 2 to 3-year payback period \\
\hline Market Potential & $\begin{array}{r}8-17 \\
\text { billion } \mathrm{ft}^{2}\end{array}$ & \\
\hline $\begin{array}{l}\text { Market-Achievable Annual } \\
\text { Energy Savings }\end{array}$ & $\begin{array}{c}0.08-0.25 \\
\text { quads }\end{array}$ & \\
\hline
\end{tabular}

As presently used to control outdoor-air intake into air-handling units, $\mathrm{CO}_{2}$-based DCV does not control contaminants from non-occupant sources and over-ventilates when the occupancy of rooms served decreases well below the design occupancy. The cost of installing $\mathrm{CO}_{2}$ sensors in each individual room to determine $\mathrm{CO}_{2}$ concentrations dynamically would be prohibitively high. Some system-specific guidance for single-zone systems is available, but consistent, reliable, verified DCV application guidance for multizone VAV systems is not available.

\subsection{Summary of Section 5}

Carbon dioxide-based DCV has been accepted as a mature technology for saving energy in commercial buildings. It has been used in many single-zone systems, but field data have shown wide ranges of energy savings.

Available control strategies all use zone $\mathrm{CO}_{2}$ concentration or the differential between the zone and outdoor $\mathrm{CO}_{2}$ concentrations to control outdoor-air intake rates.

The most recent ventilation and energy standards have included DCV and ventilation reset in their requirements. However, an exact technique to implement $\mathrm{CO}_{2}$-based $\mathrm{DCV}$ with multi-zone systems that complies with both Standard 62.1-2010 (ANSI/ASHRAE 2010) and Standard 90.1-2010

(ANSI/ASHRAE/IESNA 2010) has not been established. An ASHRAE Research Project (RP 1547) is underway to explore solutions to this need. 


\section{Conclusions}

The key conclusions from this study are:

- Although DCV for single-zone systems is relatively mature, design and implementation of multizone VAV DCV is challenging. There is some system-specific guidance for single-zone systems, but DCV application guidance for multi-zone VAV systems is not available.

- Occupancy of zones can vary considerably with time. For example, conference rooms can have highly varying occupancy over the course of a day. At times, they may be fully occupied (at the design occupancy), but at other times, occupancy may be only a fraction of the design value, or the room may be completely unoccupied (with no ventilation being required).

- Constant minimum air flow set points for terminal boxes are still determined in the field largely using rules of thumb rather than computations for each terminal box and zone. This leads to excessive fan power consumption and potentially significant unnecessary reheating of air in terminal boxes before discharge into the zones. It can also result in excessive cooling of supply air by the air handler.

- Occupancy-based control of zone ventilation rates shows promise for saving energy and improving comfort at reasonable cost compared to use of $\mathrm{CO}_{2}$ concentration measurements in each room for this purpose. Savings would result from decreased fan use, cooling, and reheating. Technology for sensing the actual occupancy numbers of the zone served by a terminal box in real time is emerging. Several technologies show promise, but none currently fully meet the needs for both adequate accuracy and sufficiently low cost. Additional development of cost effective occupancy-number sensors is still needed.

- In addition to development of new, low-cost occupancy-sensing technology, algorithms for terminal box control using occupancy number data need to be developed in parallel with the sensing technology. These algorithms should control flow rates based on real-time data, matching ventilation rates with the needs of the occupants actually in the zone served. Application of the resulting control technology will decrease the energy requirements and costs for heating, cooling and ventilating commercial buildings.

- The development of new control strategies for terminal boxes or other components of air distribution system must consider their relationships to ventilation standards (e.g., ANSI/ASHRAE 2010), which set minimum values for outdoor-air ventilation rates, and building energy standards (e.g., ANSI/ASHRAE/IESNA 2010), which establish maximum values for ventilation to control energy consumption. These standards are continuously evolving, so new control technology must maintain compatibility with their evolving requirements. 


\section{References}

Amin, I.J., A.J. Taylor, F. Junejo, A. Al-Habaibeh, and R.M. Parkin. 2008. "Automated Peoplecounting by using Low-resolution Infrared and Visual Cameras." Measurement 41(6):589599.

ANSI/ASHRAE. 1989. Standard 62.1-1989 Ventilation for Acceptable Indoor Air Quality. American Society of Heating, Refrigerating and Air-Conditioning Engineers, Atlanta, GA.

ANSI/ASHRAE. 1999. Standard 62.1-2004 Ventilation for Acceptable Indoor Air Quality. American Society of Heating, Refrigerating and Air-Conditioning Engineers, Atlanta, GA.

ANSI/ASHRAE. 2001. Standard 62.1-2004 Ventilation for Acceptable Indoor Air Quality. American Society of Heating, Refrigerating and Air-Conditioning Engineers, Atlanta, GA.

ANSI/ASHRAE. 2004. Standard 62.1-2004 Ventilation for Acceptable Indoor Air Quality. American Society of Heating, Refrigerating and Air-Conditioning Engineers, Atlanta, GA.

ANSI/ASHRAE. 2007. Standard 62.1-2007 Ventilation for Acceptable Indoor Air Quality. American Society of Heating, Refrigerating and Air-Conditioning Engineers, Atlanta, GA.

ANSI/ASHRAE. 2010. Standard 62.1-2010 Ventilation for Acceptable Indoor Air Quality. American Society of Heating, Refrigerating and Air-Conditioning Engineers, Atlanta, GA.

ANSI/ASHRAE/IESNA. 2007. Standard 90.1-2007 Energy Standard for Buildings Except Low-rise Residential Buildings. International Code Council, Inc., Washington, D.C. and American Society of Heating, Refrigerating and Air-conditioning Engineers, Inc., Atlanta, GA.

ANSI/ASHRAE/IESNA. 2010. Standard 90.1-2010 Energy Standard for Buildings Except Low-rise Residential Buildings. International Code Council, Inc., Washington, D.C. and American Society of Heating, Refrigerating and Air-conditioning Engineers, Inc., Atlanta, GA.

ASHRAE. 1992. ASHRAE Standard 55-1992, Thermal Environmental Conditions for Human Occupancy. American Society of Heating, Refrigerating and Air-Conditioning Engineers, Atlanta, GA.

ASHRAE. 2004. User's Manual: ANSI/ASHRAE Standard 62.1-2004 - Ventilation for Acceptable Indoor Air Quality. American Society of Heating, Refrigerating and Air-Conditioning Engineers, Atlanta, GA.

ASHRAE. 2007. User's Manual: ANSI/ASHRAE Standard 62.1-2007 - Ventilation for Acceptable Indoor Air Quality. American Society of Heating, Refrigerating and Air-Conditioning Engineers, Atlanta, GA. 
ASHRAE. 2009. ASHRAE Handbook Fundamentals. American Society of Heating, Refrigerating and Air-Conditioning Engineers, Atlanta, GA.

ASHRAE. 2010. User's Manual: ANSI/ASHRAE Standard 62.1-2010: Ventilation for Acceptable Indoor Air Quality. American Society of Heating, Refrigerating and Air-Conditioning Engineers, Atlanta, GA.

Avery, Gil. 1989. "Myth of Pressure-independent VAV Terminals." ASHRAE Journal 31(8):28-30.

Bauman, F.S., Charlie Huizenga, Tengfang Xu, and Takashi Akimoto. 1995. Thermal Comfort with a Variable Air Volume (VAV) System. Center for Environmental Design Research, University of California, Berkeley.

Brambley, M.R., P. Haves, S.C. McDonald, P. Torcellini, D. Hansen, D.R. Holmberg, and K.W. Roth. 2005. Advanced Sensors and Controls for Building Applications: Market Assessment and Potential R\&D Pathways. PNNL-15149, Pacific Northwest National Laboratory, Richland, WA.

Brandemuehl, M. J. and J. E. Braun. 1999. "Impact of Demand-controlled and Economizer Ventilation Strategies on Energy Use in Buildings." ASHRAE Transactions 105(Part 2).

California Energy Commission (CEC). 2008. 2008 Building Energy Efficiency Standards for Residential and Non-residential Buildings. California Code of Regulations Title 24, Part 1, CEC-400-2008-001-CMF (effective January 1, 2010).

Chen, S. and S. Demster. 1995. Variable Air Volume Systems for Environmental Quality. McGraw-Hill, New York.

Cho, Y., 2009, Minimum Airflow Reset of Single-Duct VAV Terminal Boxes. Ph.D. Dissertation, University of Nebraska - Lincoln, Lincoln, Nebraska.

Cho, Y., and M. Liu. 2008. "Optimal Terminal Box Control Algorithms for Single Duct Air Handling Units." In Proceedings of the 2nd International Conference on Energy Sustainability, ES 2008, Jacksonville, Florida, USA, August 10-14, American Society of Mechanical Engineers, New York.

Cho, Y. and M. Liu. 2009. "Minimum Air Flow Reset of Single Duct VAV Terminal Boxes." Building and Environment 44(9):1876-1885.

Emmerich, S. J., J. W. Mitchell and W. A. Beckman. 1994. "Demand-Controlled Ventilation in a Multi-Zone Office Building." Indoor Environment 3(6):331-340.

Emmerich, S. J. and A.K. Persily. 1997. "Literature Review on $\mathrm{CO}_{2}$-based Demand-controlled Ventilation." ASHRAE Transactions 103(part 2):229-243. 
Emmerich, S. J. and A.K. Persily. 2001. State-of-the-Art Review of $\mathrm{CO}_{2}$ Demand Controlled Ventilation Technology and Application. NISTIR 6729, National Institute of Standards and Technology, Gaithersburg, MD.

Fahlen, P. and H. Andersson. 1992. Demand Controlled Ventilation Systems: Sensor Tests. SP Report 1992:13, Swedish National Testing and Research Institute, Boras, Sweden.

Fisk, W.J. and A.T. De Almeida. 1998. "Sensor-based Demand-Controlled Ventilation: A Review." Energy and Buildings 29(1):35-45.

Fisk, W. J., D. Faulkner and D. P. Sullivan. 2007. "A Pilot Study of the Accuracy of $\mathrm{CO}_{2}$ Sensors in Commercial Buildings." In IAQ 2007: Healthy and Sustainable Buildings, Baltimore, MD, Oct. 14-17, 2007. American Society of Heating, Refrigerating and Air-Conditioning Engineers, Atlanta, GA.

Frank, D.. 2011. Room-based Occupancy Sensors M\&V Grouse Mountain Lodge Whitefish, MT, Bonneville Power Administration, Portland, OR.

GE Sensing. 2006. "Reference Guide for Integrating $\mathrm{CO}_{2}$ DCV with VAV Systems." Accessed 14 March 2012 at http://www.ge-mcs.com/download/appnotes/930_139A.pdf.

Hashimoto, K., M. Yoshinomoto, S. Matsueda, K. Morinaka and N. Yoshiike. 1996. "Development of People Count System using Human Information Sensor." In Technical Digest of the 14th Sensor Symposium, editor, D. Gakkai, pp. 83-86. June 4 - 5, 1996, Kawasaki, Japan. Institute of Electrical Engineers of Japan, Tokyo.

Hashimoto, K., T. Tsuruta, K. Hishimura, K. Morinaka, M. Kawaguri, and N. Yoshiike. 1997a. "Characteristics of Pyroelectric Infrared Array Detector made of PbTiO3 Ceramics." Japan J. Appl. Phys. 36:3553-3557.

Hashimoto, K., M. Yoshinomoto, S. Matsueda, K. Morinaka, and N. Yoshiike. 1997b. "Development of People-counting System with Human-information Sensor using Multielement Pyroelectric Infrared Array Detector." Sensors and Actuators A:Physical 58(2):165171.

Hashimoto, K., C. Kawaguchi, S. Matsueda, K. Morinaka, and N. Yoshiike. 1998. "Peoplecounting System using Multisensing Application." Sensors and Actuators A: Physical 66(13):50-55.

Hashimoto, K., T. Tsuruta, K. Morinaka, and N. Yoshiike. 2000. "High Performance Human Information Sensor." Sensors and Actuators A: Physical 79(1):46-52. 
Hendrix, J. and J. Kohl. 2009. Zigbee Overview. Zigbee Alliance, San Ramon, CA. Accessed on 2 April 2012 at www.zigbee.org/imwp/download.asp?ContentID=15157.

Houghton, D. 1995. Demand-controlled Ventilation. Teaching Buildings to Breathe. Tech Update, TU-90-10, E-Source, Boulder, CO.

IEEE. 2003. IEEE 802.15.4, Part 15.4: Wireless Medium Access Control (MAC) and Physical Layer (PHY) Specifications for Low-Rate Wireless Personal Area Networks (LR-WPANs). The Institute of Electrical and Electronics Engineers, Inc., New York.

Janssen, J. E. 1999. "History of Ventilation and Temperature Control." ASHRAE Journal 41(10):47-52.

Jones, J., D. Meyers, H. Singh and P. Rojeski 1997. "Performance Analysis for Commercially Available $\mathrm{CO}_{2}$ Sensors." Journal of Architectural Engineering 3(1): 25-31.

Kamthe, A., J. Lun, D. Matthew, and A. Cerpa. 2009. "SCOPES: Smart Cameras Object Position Estimation System." In Wireless Sensor Networks, Proceedings of 6th European Conference, EWSN 2009, Utz Rödig, editor, pp. 279-295. February 11-13, 2009. Cork, Ireland. Springer-Verlag, Berlin, Germany.

Knoespel, P. D., J. W. Mitchell and W. A. Beckman. 1991. "Macroscopic Model of Indoor AirQuality and Automatic-Control of Ventilation Air-Flow." ASHRAE Transactions 97(Pt 2): 1020-1030.

Liu, G., B. Liu, W. Wang, J. Zhang, R. A. Athalye, D. Moser, E. Crowe, N. Bengtson, E. Mark, L. Webster, S. Clem, B. McGinnis, P. Schlattmann and M. Hatten. 2011. Advanced Energy Retrofit Guides (AERG) - Practical Ways to Improve Energy Performance for Office Buildings. PNNL-20761, Pacific Northwest National Laboratory, Richland, WA.

Liu, G., and M.R. Brambley. 2011. "Occupancy Based Control Strategy for Variable-Air- Volume (VAV) Terminal Box Systems." ASHRAE Transactions 117(2):244-252.

Liu, M., M. Abbas, Y. Zhu, and D.E. Claridge. 2002. "Terminal Box Air Flow Reset: An Effective Operation and Control Strategy for Comfort Improvement and Energy Conservation." Paper ESL-HH-02-05-10, In Proceedings of the 13th Symposium on Improving Building Systems in Hot and Humid Climates, Houston, TX, May 20-22, 2002. Texas A\&M University, College Station, TX. Accessed on 31 March 2012 at http://repository.tamu.edu/handle/1969.1/ 4538.

Lu, T., X. Lü and M. Viljanen. 2011. "A Novel and Dynamic Demand-controlled Ventilation Strategy for $\mathrm{CO}_{2}$ Control and Energy Saving in Buildings." Energy and Buildings 43(9):24992508. 
Liwerant, E. 2008. "VAV-box Selection, Code Conformance: Demystifying the Application of Cooling-with-reheat VAV Terminals." Heating, Piping, Air Conditioning Engineering 80(2): 44-46.

Mansson, L.G. 1992. Demand Controlled Ventilating Systems. Case Studies. International Energy Agency, Annex 18, Energy Conservation in Buildings and Community Systems Program. Swedish Council for Building Research, Stockholm Sweden.

Mansson, L. 1994. "Demand Controlled Ventilation Systems in Non-industrial Buildings." In Proceedings of the European Conference on Energy Performance and Indoor Climate in Buildings, Vol. 3, pp. 895-900. November 24-26, 1994, Lyon, France.

Mansson, L.-G. and S.A. Svennberg. 1992. Demand Controlled Ventilating Systems. Source Book. International Energy Agency, Annex 18, Energy Conservation in Buildings and Community Systems Program. Swedish Council for Building Research, Stockholm Sweden.

Meier, S. 1998. "Demand-Controlled Ventilation - Requirements and Control Strategies." In Proceedings of Roomvent '98: The 6th International Conference on Air Distribution in Rooms, Vol. 1, editors, E. Mundt and T-G Malmstrom, pp. 205-212. June 14-17, 1998, Stockholm, Sweden.

Meyn, S.P., A. Surana, Y. Lin, S. M. Oggianu, S. Narayanan, and T. Frewen. 2009. "A SensorUtility-network Method for Estimation of Occupancy Distribution in Buildings." In Proceedings of the $48^{\text {th }}$ IEEE Conference on Decision and Control, Shanghai, China, December 15-18, 2009. Institute of Electrical and Electronic Engineers, New York.

Murphy, J. 2005. "CO 2 -Based Demand-Controlled Ventilation with ASHRAE Standard 62.12004." Trane Engineers Newsletter. 34-5:1-8, Trane, Lacrosse, WI. Access on 31 March 2012 at http://www.trane.com/Commercial/DNA/View.aspx?i=673.

Nassif, N. 2012. "A Robust $\mathrm{CO}_{2}$-based Demand-controlled Ventilation Control Strategy for Multizone HVAC Systems." Energy and Buildings 45:72-81.

Nassif, N. and M. Zaheer-uddin. 2007. "Simulated Performance Analysis of a Multizone VAV System under Different Ventilation Control Strategies." ASHRAE Transactions 113(1):617629.

Nassif, N., S. Kajl and R. Sabourin. 2005. "Ventilation Control Strategy using the Supply $\mathrm{CO}_{2}$ Concentration Setpoint." HVAC\&R Research 11(2):239-262.

PG\&E. 2007. Advanced Variable Air Volume System Design Guide, Pacific Gas and Electric Company, San Francisco. 
Raatschen, W. 1990. Demand Controlled Ventilation Systems: State of the Art Review. International Energy Agency, Annex 18, Energy Conservation in Buildings and Community Systems Program. Swedish Council for Building Research, Stockholm, Sweden.

Raatschen, W. 1991. "Demand Controlled Ventilating Systems. Sensor Market Survey." International Energy Agency, Annex 18, Energy Conservation in Buildings and Community Systems Program. Swedish Council for Building Research, Stockholm, Sweden.

Rickelton, D. and H.P. Becker. 1972. "Variable air volume." ASHRAE Journal 14(9), 31-55.

Sand, J.R. 2004. Demand-Controlled Ventilation Using $\mathrm{CO}_{2}$ Sensors. Federal Energy Management Program, U.S. Department of Energy, Washington, DC.

Schell, M. and D. Inthout, 2001. "Demand Control Ventilation Using $\mathrm{CO}_{2}$." ASHRAE Journal 43(2):18-24.

Schell, M. B., S. C. Turner and R. O. Shim. 1998. "Application of $\mathrm{CO}_{2}$-based Demand-controlled Ventilation using ASHRAE Standard 62: Optimizing Energy Use and Ventilation." In ASHRAE Transactions 104(Part 2):1231-1225.

Smeed, J. 2007. "Variable Air Volume Systems-Not the Latest but Still the Best." Ecolibrium 6(8):22-29. Available at http://mail.airah.org.au/downloads/2007-09-01.pdf.

Sorensen, B.R. 1996. "Simulation of a Small VAV Plant." In Proceedings of $7^{\text {th }}$ International Conference on Indoor Air Quality and Climate, Indoor Air '96. Vol. 2, pp. 199-204. July 21-26, 1996, Nagoya, Japan.

Stanke, D. 1999. "Ventilation Through the Years: A Perspective." ASHRAE Journal 41(8): 40-43.

Stanke, D. 2006. "Standard 62.1-2004: System Operation: Dynamic Reset Options." ASHRAE Journal 48(12):18-32.

Stanke, D. 2010. “Dynamic Reset for Multiple-zone Systems. (Standard 62.1-2007)." ASHRAE Journal 52(3):22-35.

Stein, J. 2005. "VAV Boxes." Heating, Piping, Air Conditioning Engineering 77(11):40-44.

Stipe, M. 2003. Demand-Controlled Ventilation: A Design Guide. Oregon Office of Energy, Salem, OR. Accessed on 12 March 2012 at http://www.oregon.gov/energy/cons/bus/dcv/ docs/dcvfuide.pdf.

Taylor, S. 2006. “COㄱ-based DCV Using 62.1-2004.” ASHRAE Journal 48(5):67-75.

Taylor, S., and J. Stein. 2004. "Sizing VAV Boxes." ASHRAE Journal, 46(3):30-36. 
Thornton, B. A., M. I. Rosenberg, E. E. Richman, W. Wang, Y. Xie, J. Zhang, H. Cho, V. V. Mendon, R. A. Athalye and B. Liu. 2011. Achieving the 30\% Goal: Energy and Cost Savings Analysis of ASHRAE Standard 90.1-2010. PNNL-20405, Pacific Northwest National Laboratory, Richland, WA.

Warden, D. 2004. "Supply Air $\mathrm{CO}_{2}$ Control of Minimum Outdoor Air for Multiple Space Systems." ASHRAE Journal 46(10):26-35.

Won, D. and W. Yang. 2005. The State of-the-Art in Sensor Technology for Demand-Controlled Ventilation. IRC-RR-243, National Research Council Canada, Ottawa, Canada.

Xu, X., S. Wang, Z. Sun and F. Xiao. 2009. "A Model-based Optimal Ventilation Control Strategy of Multi-zone VAV Air-conditioning Systems." Applied Thermal Engineering 29(1):91-104.

Yoshiike, N., K. Morinaka, K. Hashimoto, M. Kawaguri, and S. Tanaka. 1999. "360 Direction Type Human Information Sensor." Sensors and Actuators A: Physical 77(3):199-208.

Yoshinaga, S., A. Shimada, and R. Taniguchi. 2010. "Real-time People Counting using Blob Descriptor." Procedia - Social and Behavioral Sciences, The 1st International Conference on Security Camera Network, Privacy Protection and Community Safety, 2(1):143-152.

Zhu, Y., Liu, M., J. Zhou,, T. Batten, H. Noboa, D. Claridge, D. Turner, C. Cameron,, B. Keeble, and R. Hirchak. 2000. "Optimization Control Strategies for HVAC Terminal Boxes." Paper ESL-HH00-05-34. In Proceedings of the 12th Symposium on Improving Building Systems in Hot and Humid Climates, San Antonio, Texas, May 15-17, 2000. Texas A\&M University, College Station, TX. Accessed on 31 March 2012 at http://repository.tamu.edu/handle/ 1969.1/6804.

Zigbee. 2007. Zigbee Specification. Zigbee Standards Organization, San Ramon, CA. 


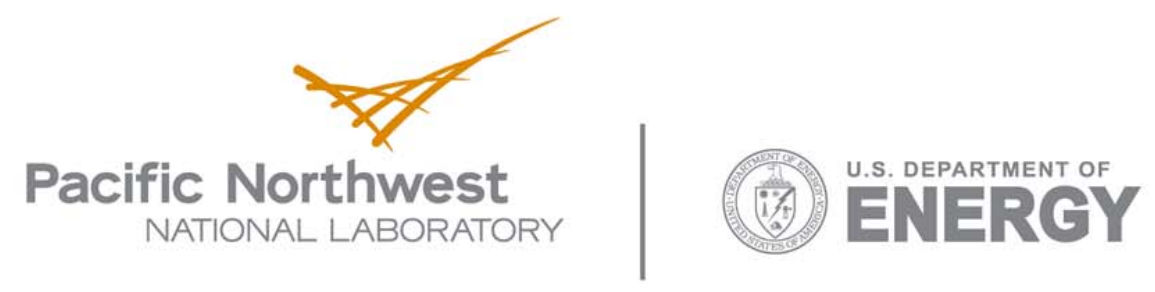

902 Battelle Boulevard

P.O. Box 999

Richland, WA 99352

1-888-375-PNNL (7665)

www.pnl.gov 